\title{
Social Robots on a Global Stage: Establishing a Role for Culture During Human-Robot Interaction
}

\author{
Velvetina $\operatorname{Lim}^{1}$ (D) Maki Rooksby ${ }^{(D)} \cdot$ Emily S. Cross $^{2,3_{(D}}$
}

Accepted: 1 October 2020 / Published online: 11 November 2020

(c) The Author(s) 2020

\begin{abstract}
Robotic agents designed to assist people across a variety of social and service settings are becoming increasingly prevalent across the world. Here we synthesise two decades of empirical evidence from human-robot interaction (HRI) research to focus on cultural influences on expectations towards and responses to social robots, as well as the utility of robots displaying culturally specific social cues for improving human engagement. Findings suggest complex and intricate relationships between culture and human cognition in the context of HRI. The studies reviewed here transcend the often-studied and prototypical east-west dichotomy of cultures, and explore how people's perceptions of robots are informed by their national culture as well as their experiences with robots. Many of the findings presented in this review raise intriguing questions concerning future directions for robotics designers and cultural psychologists, in terms of conceptualising and delivering culturally sensitive robots. We point out that such development is currently limited by heterogenous methods and low statistical power, which contribute to a concerning lack of generalisability. We also propose several avenues through which future work may begin to address these shortcomings. In sum, we highlight the critical role of culture in mediating efforts to develop robots aligned with human users' cultural backgrounds, and argue for further research into the role of culturally-informed robotic development in facilitating human-robot interaction.
\end{abstract}

Keywords Social robotics $\cdot$ Human-robot interaction $\cdot$ Culture $\cdot$ Individualism-collectivism $\cdot$ Human cognition $\cdot$ Embodied social interaction

\section{Introduction}

Social interactions form the foundation of every human society, as our abilities to perceive, respond to, and coordinate behaviour with other beings are necessary for us to survive and thrive in a social world. To coordinate successful interactions with others, the human brain must decipher a rich myriad of social signals produced by other people [1]. However, this ability is starting to be stretched and challenged as the presence of socially assistive robots in human society grows. Over a decade ago, Microsoft founder Bill Gates

\section{Emily S. Cross}

Emily.cross@mq.edu.au

1 School of Management, University College London, London, UK

2 Institute of Neuroscience and Psychology, University of Glasgow, Glasgow, Scotland

3 Department of Cognitive Science, Macquarie University, Sydney, Australia prophesized a revolution in the robotics industry that would see staggering leaps in the progress and sophistication of robots, and predicted "a robot in every home" in the near future [2]. While the ubiquity of home robots has yet to be realised, the number of robotics-related start-up companies launching annually continues to exponentially increase [3], with a growing percentage focusing on the development of companion robots for the home or assistance robots to serve in complex, human-interactive contexts, like schools, hospitals and care homes.

As interest in and the development of such social robots continues apace, crucial questions arise concerning how human users in general might perceive and interact with these agents. Particularly, pertinent questions remain concerning the extent to which our thoughts, feelings, and behaviours toward robots are shaped by our cultural backgrounds. The challenge particularly lies in the fact that we possess no evolutionary information about prior social interactions with such agents, as we do with human agents [4]. Based on the cognitive gadget hypothesis [5, 6], humans develop cru- 
cial cognitive mechanisms through cultural social learning processes that successfully survived the evolution of time. As such, socio-cognitive mechanisms developed in response to the recent introduction of social robots are likely to be nascent. While the number of research laboratories investigating human responses to robots continues to grow, an important concurrent development is that the impact of culture is increasingly being considered when developing and evaluating new robotics technologies. Admittedly, 'culture' is neither a unitary nor an easily definable construct, and anthropologists have criticized many attempts made by those working in the behavioural sciences to quantify cultural influences on human behaviour [7]. However, to generate richer, interdisciplinary characterization of complex phenomena that are at the heart of successful social interactions between humans and robots (such as perspective taking, empathy, and self-other understanding), the challenge remains to appropriately and sensitively apply existing theories of culture to understand, explain, and predict how cultural elements influence human social cognition and behaviour [8].

In this piece, we begin by surveying the current state of the art in terms of theoretical foundations for cultural differences in people's attitudes and approaches to robots, and then review empirical research investigating HRIs that specifically evaluates or manipulates the influence of participants' culture. We begin by exploring different cultures' relationships to ideas related to robots, and then move on to more precisely define what we mean by culture, and the type of cultural influences on social interactions that might be particularly relevant in the domain of human-robot interaction (HRI). We survey a broad literature from social robotics, social cognition, and behavioural psychology, in order to build the most complete picture possible regarding the state of knowledge in this domain. Integrating empirical findings derived from these parallel research domains, we aim to build and extend theories of culture that are salient when people encounter robots. Further, we also highlight key current limitations in the literature, namely methodological inconsistency and the lack of theory building. In a sense, this review serves as a call for a more integrative approach when investigating HRIs that strives to take into account individual differences in human participants' cultural backgrounds and the cultural context of the experiment, as these factors indelibly shape cognition and the outcomes of human-robotic encounters.

Whilst a review that tackles some related content has been published recently [9], this earlier review focused more specifically on people's attitudes towards humanoid and animal social robots across different cultures, for purposes of healthcare usage. The aim of the current review is to provide a general overview of how HRIs, more broadly construed, are influenced by culture through the development of preconceived expectations, shaping differential responses during interactions, and implications for future robotic design.

\subsection{Aims of Current Paper}

Our overarching aim is to establish a case for why cultural considerations with respect to our encounters with robots are important to address. We present a narrative synthesis of the evidence to date on the impact of culture on HRIs. This approach enables us to identify elements of an individual's cultural background relevant to HRI and consider to what extent these elements are a critical part of our experience in interacting with social robots. Our ultimate aim is to articulate priority areas for future research questions regarding more refined roles of culture as well as its extent during HRI.

To achieve these aims, we first introduce different perspectives on how culture and robotics are intertwined to establish a context for understanding the importance of culture as a causal influence in shaping HRIs. Then, we review 50 studies on how culture influences our expectations, attitudes, and behaviours before, during, and after interactions with robots. While Table 1 provides an overview of study characteristics and research questions of these 50 studies, these studies are visualised in terms of sample size distribution in Fig. 1.

\subsubsection{The Intertwining of Culture and Robotics: A Sociological Perspective}

The extant research on HRIs suggests that people's interactions with robots are guided by our existing experience and expectations, much like during human-human interaction (HHI) (e.g., [10]). In turn, it may follow that what we experience, think or feel when interacting with a robot should inform our future interactions with such agents. In this section, we ask how an individual's cultural affiliation and identity might play a role in this process, and articulate what existing research can tell us regarding how and to what extent cultural background impacts emotions, cognition and perception of robots during HRI.

While detailed consideration of the origins of culture itself is beyond the remit of this paper, relevant discussions have recently been published that consider the impact of culture and philosophy in an HRI context (e.g., [11]). Philosophical systems of the West (e.g. Europe and the Americas) have been contrasted with those of the East (e.g. Asia and the Middle East), with the former seeking a systematic, consistent and comprehensive understanding of our universe, while the latter taking a more holistic or circular view in understanding our world. For example, Western history of thought is marked by major changes in thinking regarding human existence in order to balance new ideas with maintaining consistency of thought systems (e.g., Freud on the unconscious mind). On the other hand, equivalent history in the East has been observed to have taken a much more continuous trajectory. For example, in Japan, there is an inclination toward animism, and the Buddhist belief that souls reside 


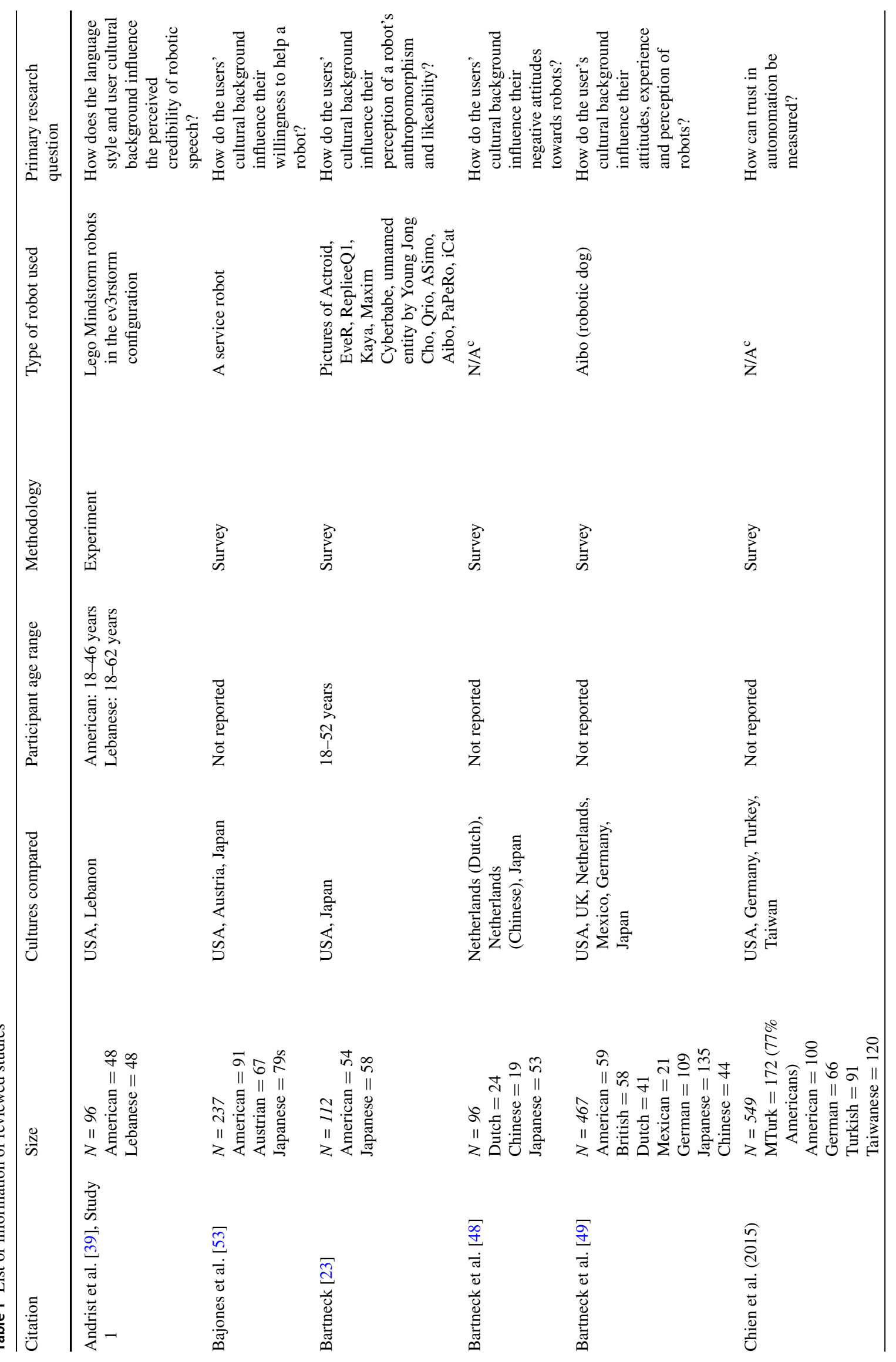




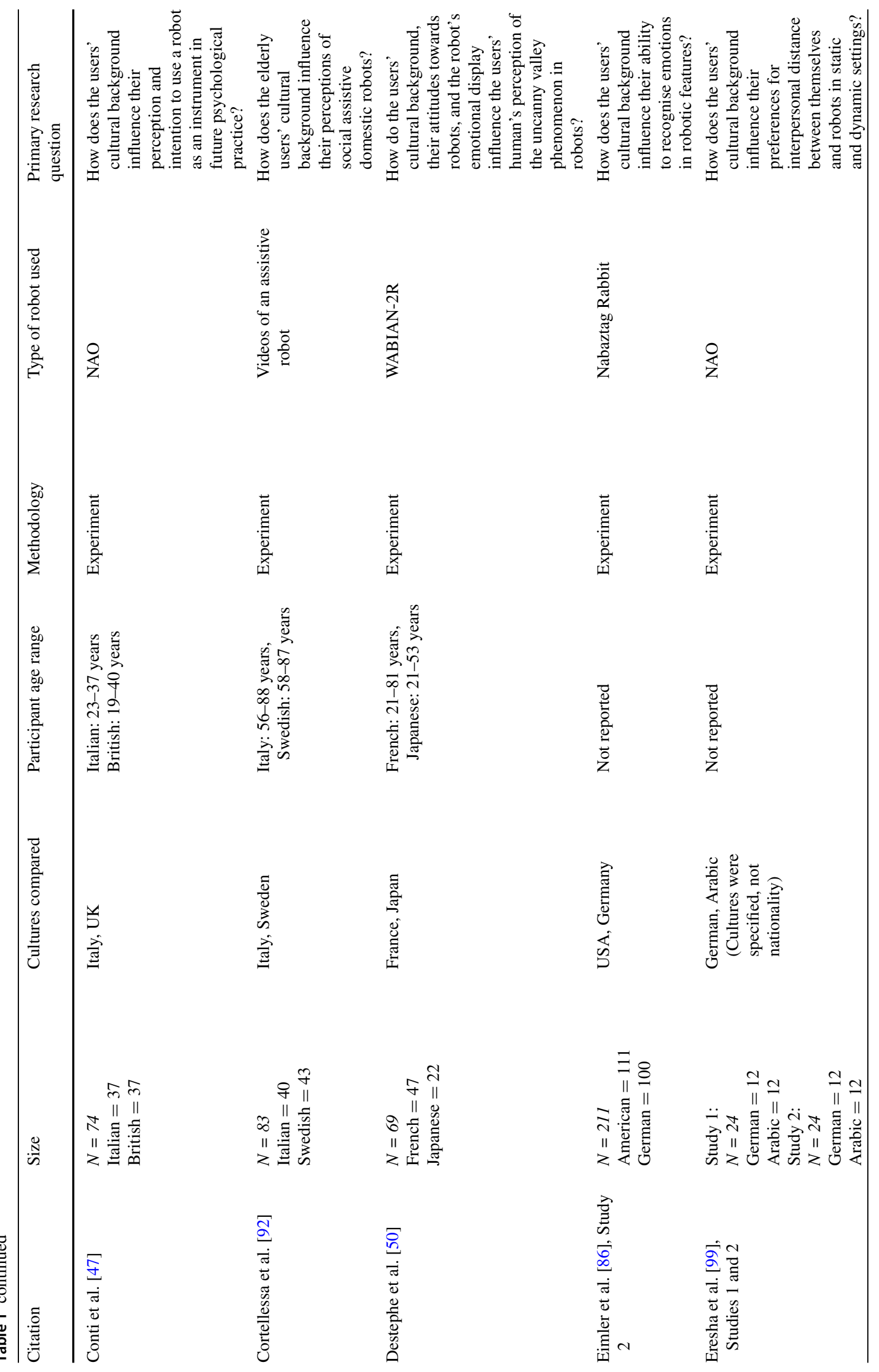




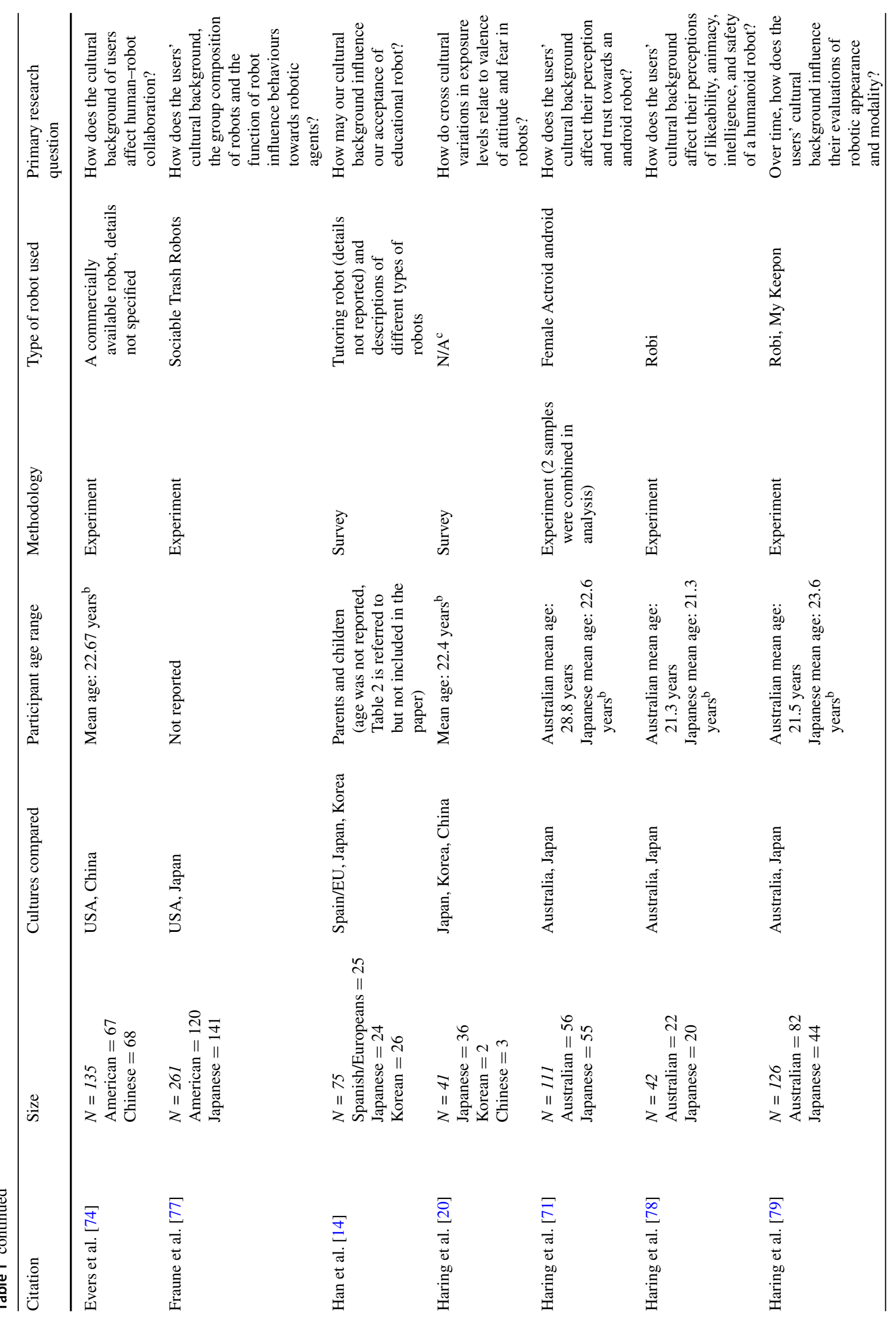




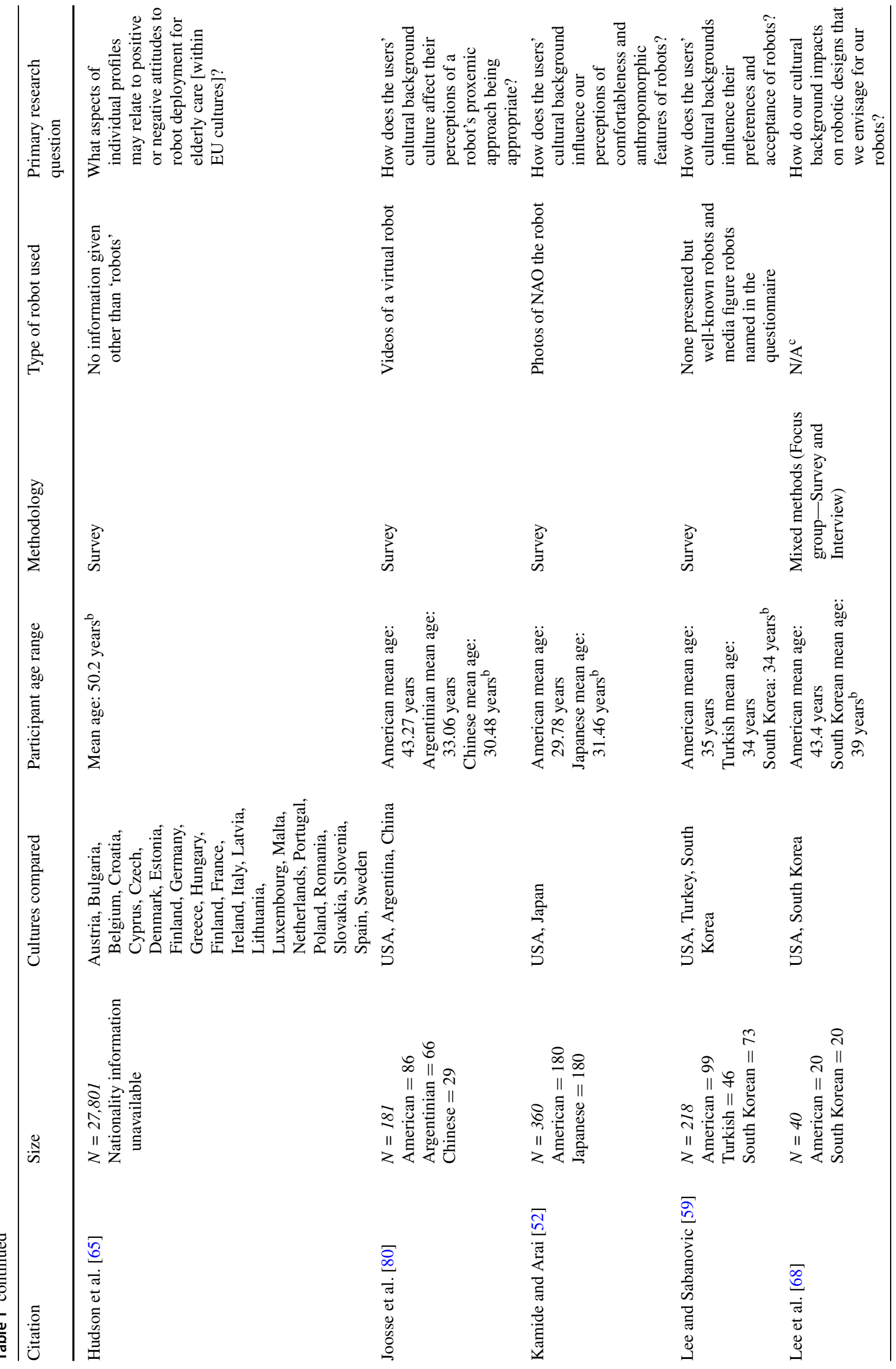




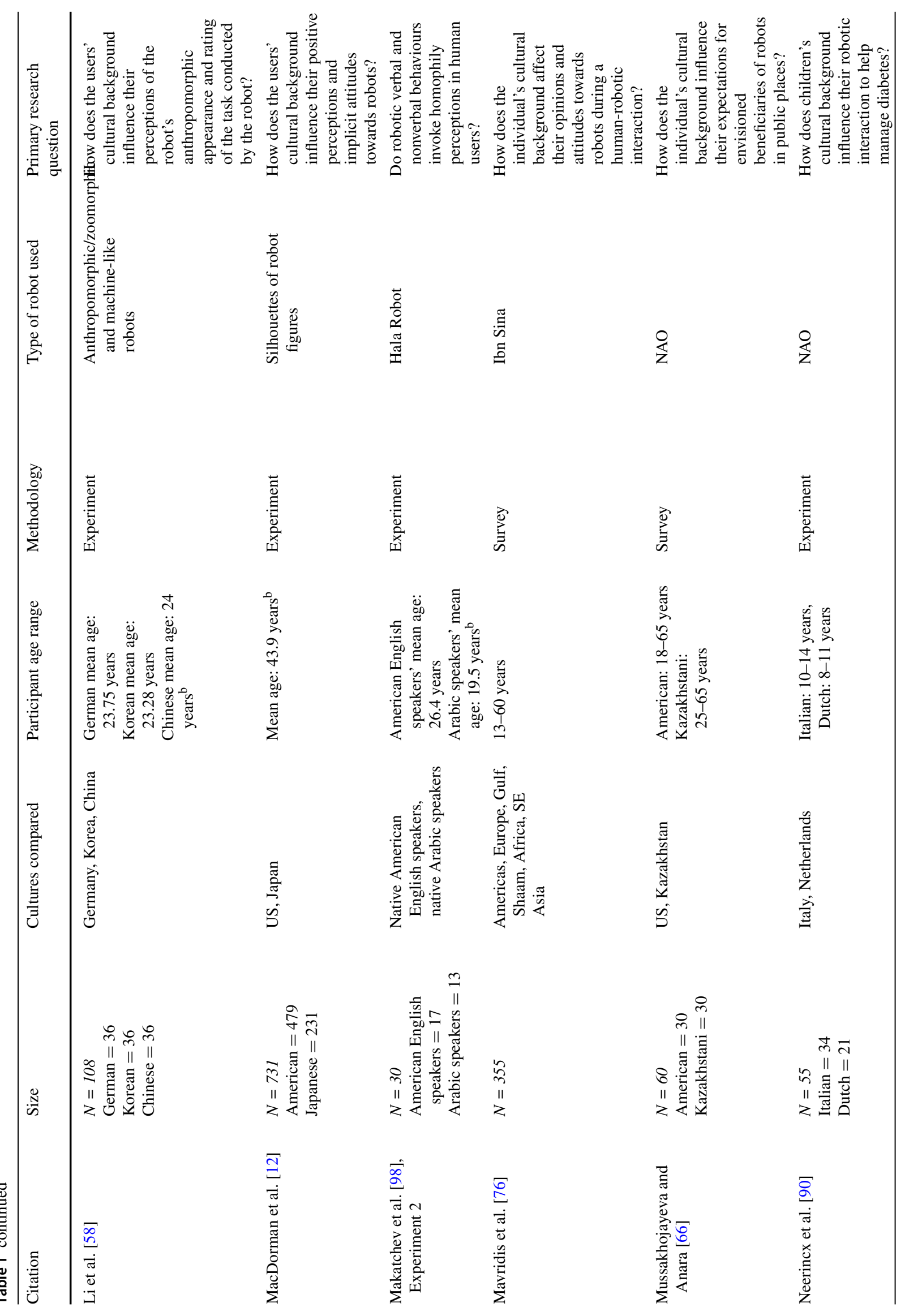




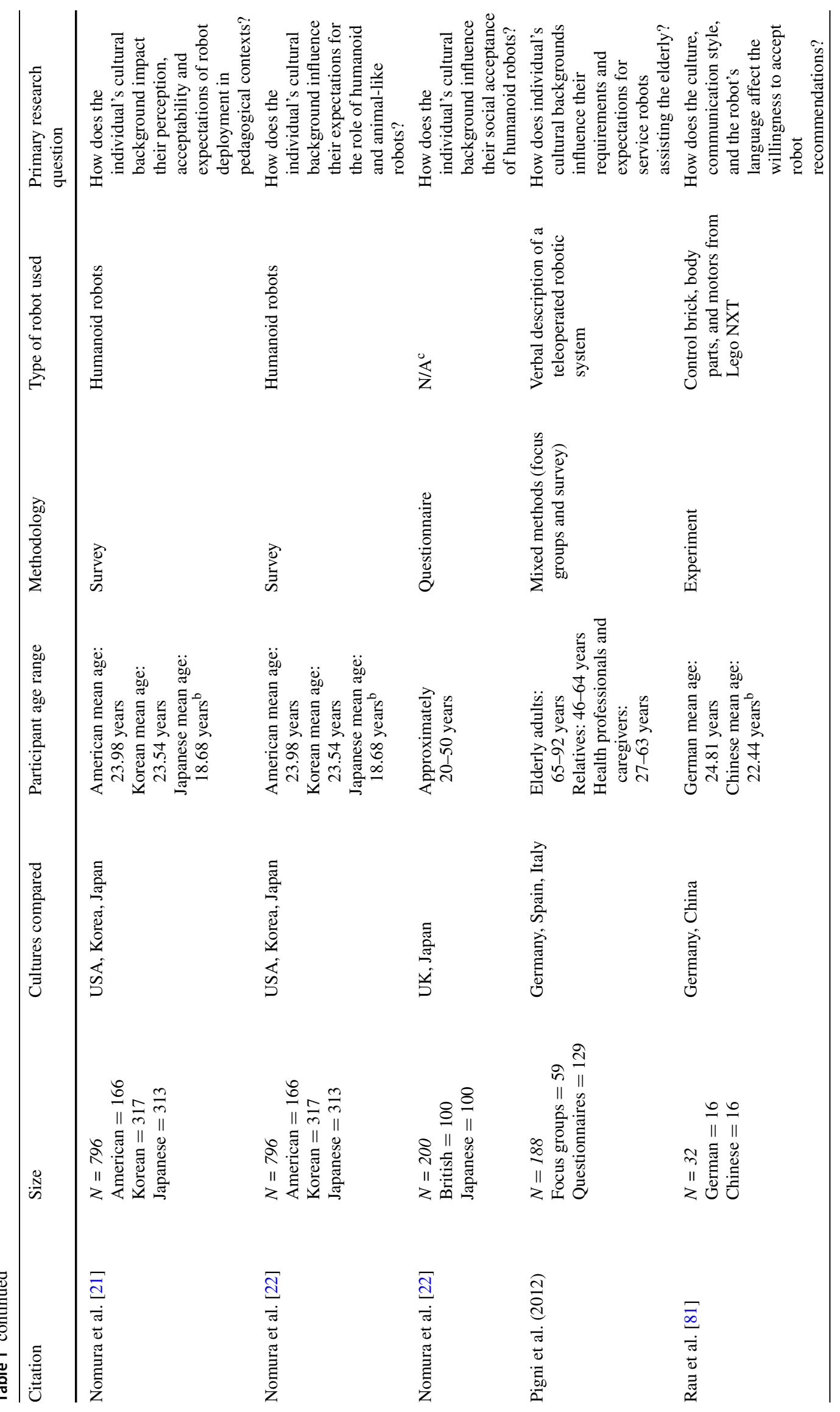




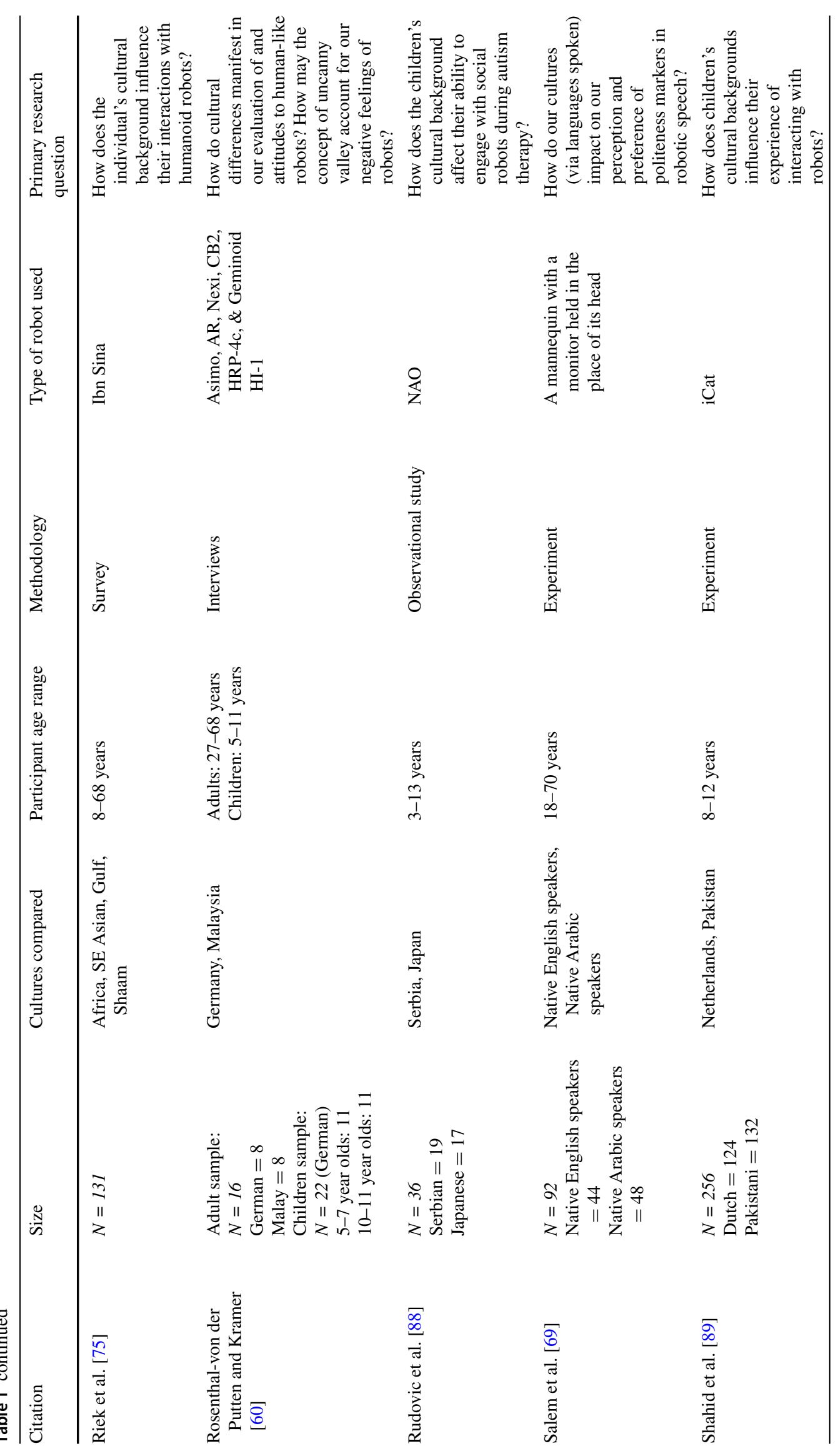




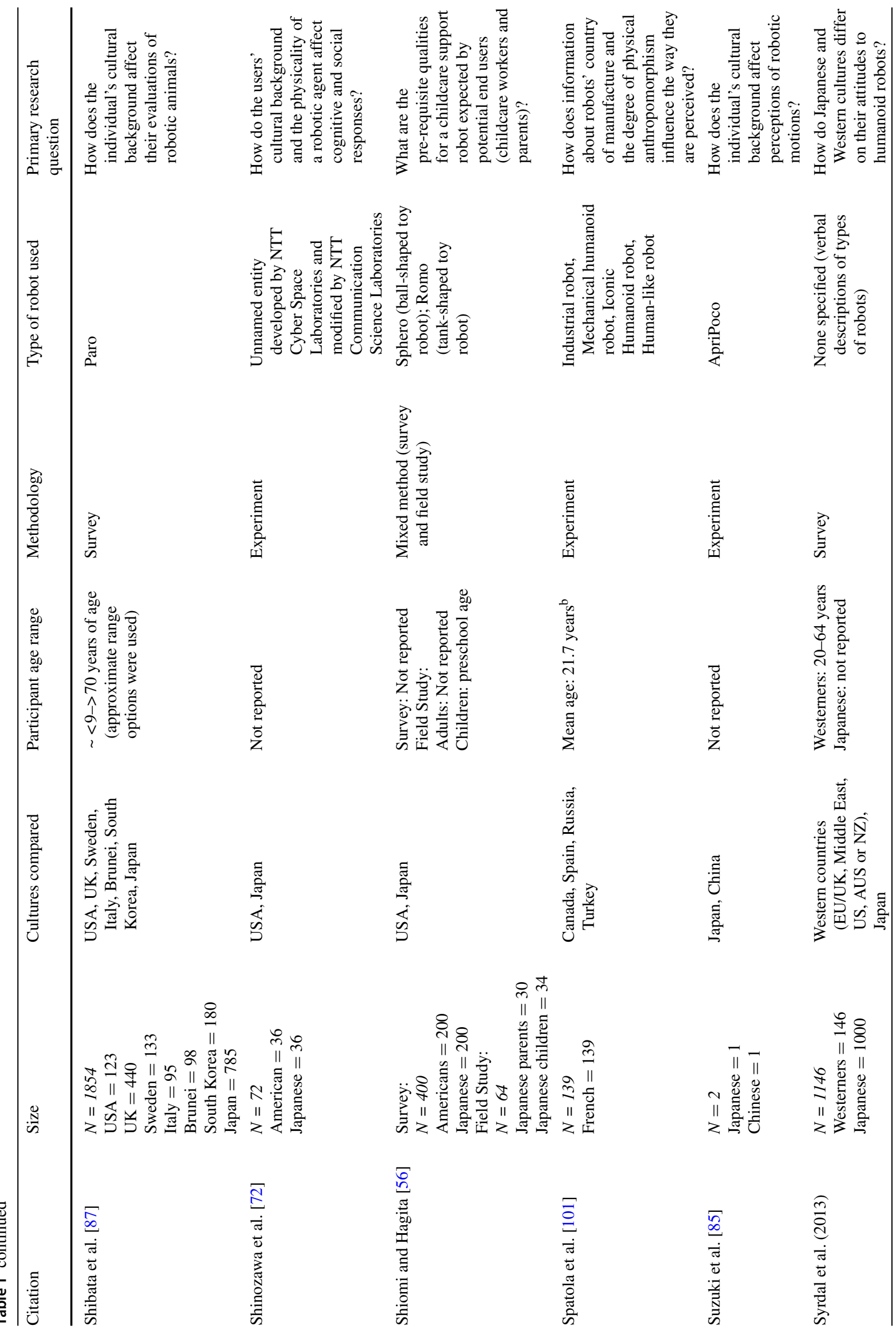




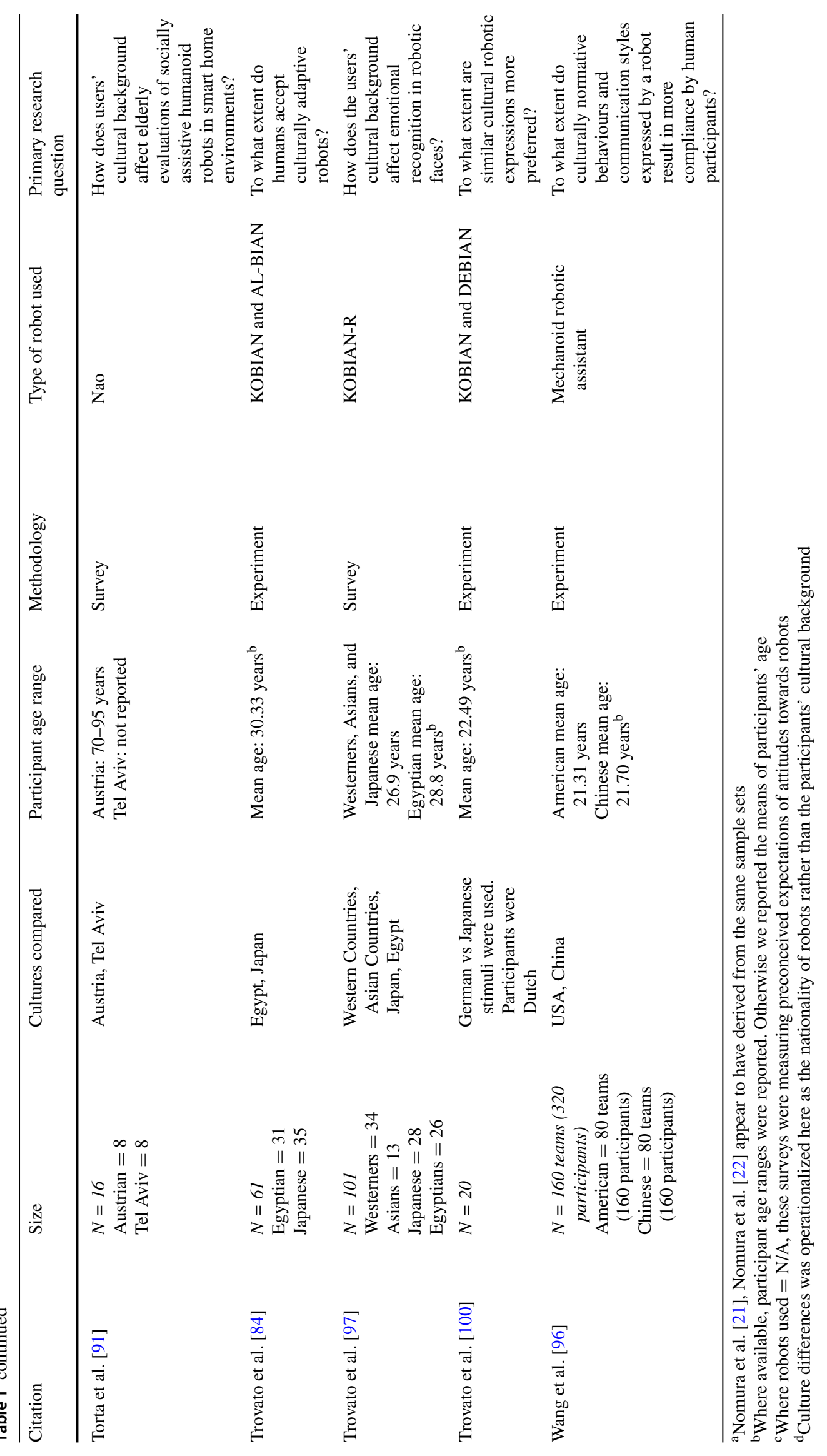




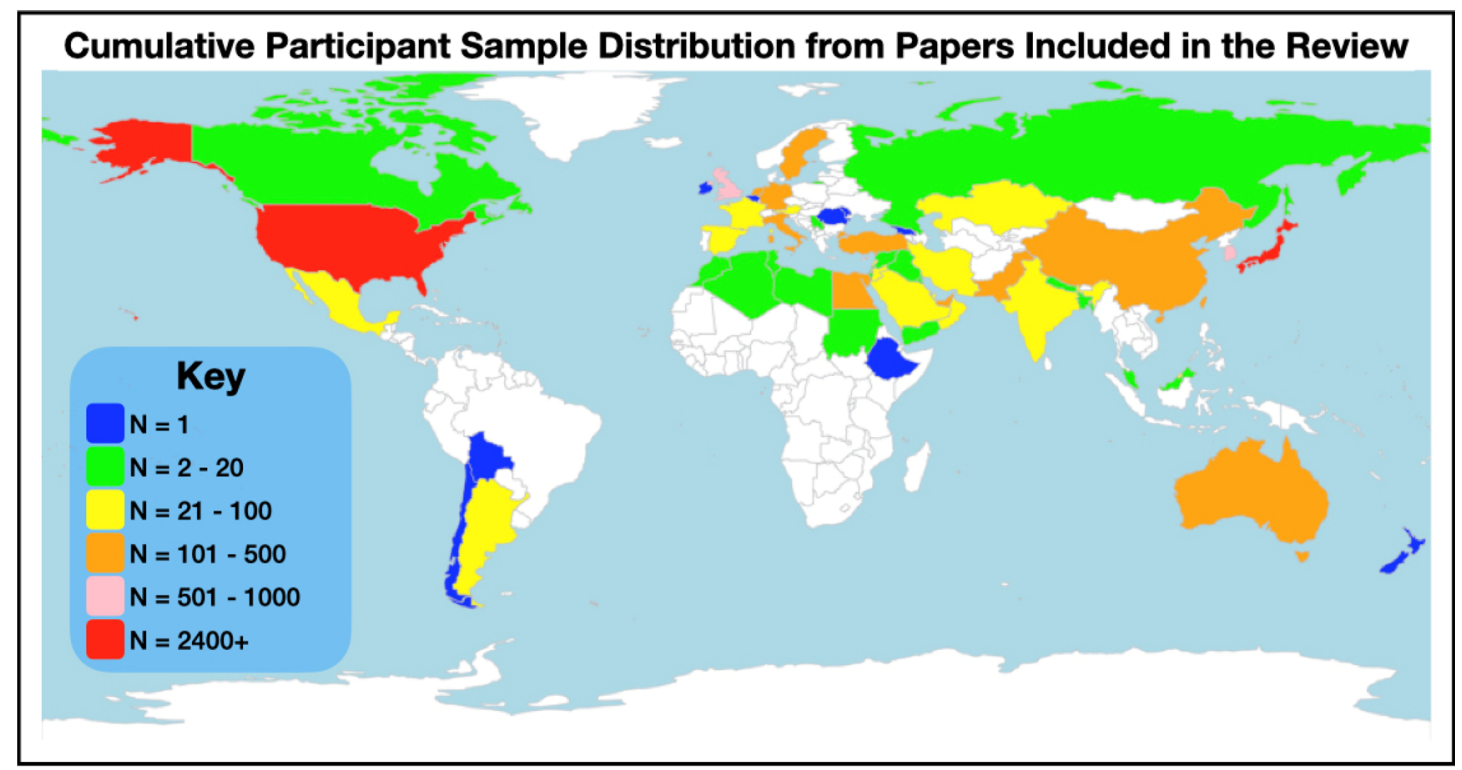

Fig. 1 A world map schematic representing the participant samples of 49 of the 50 studies reviewed in this paper, based on participant demographics reported by each paper. The participant sample of 27,801 reported by Hudson et al. [65] was excluded from this map due to this study not reporting detailed numbers for participant samples collected from each of the 28 European countries surveyed in this study in all things whether living or not. Some suggest that such cultural and philosophical leanings may induce more readiness in acceptance of robots among Japanese people [12]. Today, due to globalization resulting in the near instantaneous spread of information and increasing exposure to and interactions with individuals from different cultures, these so-called traditional values may not have the influence they once did (at least in some cultures). Still, such values that are rooted in our culture and heritage are likely to be internalized and passed on across generations. As a consequence, this makes cultural research a complex challenge with multiple layers of enmeshed constructs, and even more so for studying the role of culture during HRI.

\subsection{Cultural Roots of Robotics History}

The history of robotics is, by definition, multi-disciplinary in nature at the intersection of science, engineering, philosophy, politics, as well as cultural studies. The word 'robot' was created by the Western literature, in a science fiction play titled Rossum's Universal Robots [13]. The term robot (or robota in the original Czech) means "hard work" in Czech and other Eastern European languages. Accordingly, in the play, Capek's robots were postulated as helping machines to free up people's time and capacity for more creative activities. This theme is echoed often in the early history of robotics, where robots are often seen as a symbol of labour or a service provider, most of which were contributed by Western countries [14]. In contrast, major advancements in social robotics have been made in Asian countries, whose cultures seem far more amenable for robots to take human form and perform more human-like roles. Some have even suggested that this is apparent in translations of the word robots into Asian languages, such as Japanese (人造人間 · artificial human) or Chinese (機器人 · machine human; [14]). While arbitrariness is entwined in human languages, and the relationship between language and thought is not necessarily causal (Sapir-Whorf hypothesis $[15,16]$ ), these are certainly curious coincidences. Fascination with robots began to take hold in Japan during the post-war period, and the country's researchers and engineers have since been at the forefront of innovation and development of robots, in particular, service robots. The Japanese government is globally renowned for promoting the development and use of social robots to address the country's social challenges posed by advancing population age and falling birth-rates [17]. It is possible that these political and industrial interests are somewhat reflected by the positive representations of robots in Japanese media, such as anime and manga, which frequently included portrayals of robots as kind and patient (Doraemon [18]) or with a strong sense of justice (Astro Boy [19]) [14]. This is often contrasted with much more mixed examples of robots in the Western media, ranging from those friendly and benign to evil and violent (film examples including Wall-E, I, Robot, or Terminator [20]). Indeed, some research suggests that Japanese people expect robots to have a more human-like appearance (i.e., prefer humanoid robots) and tend to grant greater autonomy to humanoid robots as compared to Korean 
or American participants ([21, 22], but see [23]). In Japan today, robots assist elderly people with shopping [24], an autonomous wheelchair robot transports people with mobility issues [25], and an assistive pet robot, Paro, interacts with and comforts elderly individuals with dementia [26]. Furthermore, attempts have been made to develop robots to address so-called generation gaps, for example by connecting toddlers with the elderly [27].

\subsubsection{The Intertwining of Culture and Robotics: A Psychological Perspective}

Culture shapes each of our social interactions. Not only does culture influence how we function as a social group, but it also affects the way we think about, perceive, and understand other individuals and our surroundings [28]. Given the globalised multicultural world we live in today, individuals are exposed to and engage in a diverse range of cultural norms and practices. In this paper, we operationalise culture as national culture - values, norms, and practices that are undertaken by a country. Particularly, we focus on the dichotomy of individualism-collectivism as a cultural perspective that has been observed as a major theoretical basis for this line of HRI research.

\subsection{Individualism-Collectivism: A Dimension of Culture}

Individualism-collectivism is one of the main dimensions of culture identified to represent individuals' representations of themselves in relation to others [29]. Coined by Hofstede [30] as a psychological dimension to explain human behaviour within organisations, this construct became of high interest to cross-cultural psychologists as a means of explaining the variation of individual behaviour depending on their group membership to national cultures [29, 31-33]. Within this broad framework, researchers examine to what extent an individual's self is defined by their relationships with others, and how that affects their attitudes, perceptions, and behaviours as individuals [31]. Highly individualistic cultures are characterised by members who value independence, focus on themselves, engage in explicit styles of communication, and their "identity is in the person" [34, p. 89]. On the other end of the spectrum, individuals in highly collectivistic cultures exhibit more interdependent behaviours and attitudes, focusing more on their relationships with others, which are often characterised by implicit styles of communication, and the sense of self for individuals from more collectivist cultures reflects the nature and values of their social group.

Whilst other conceptual frameworks conceive of individualism and collectivism as co-existing elements that constitute every individual's self-construct [35-37], the bulk of existing research on the influence of culture on HRI utilises Hofstede's definition of individualism-collectivism as a continuum. As such, we choose to operationalise individualism-collectivism in this review as a continuum in line with the current theoretical underpinnings of cross-cultural HRI research. However, we will subsequently focus on how the continuum perspective of individualism-collectivism can be better elaborated and linked to explain empirical findings, than is currently done.

\subsection{Setting The Stage For Successful Human-Robotic Social Interactions}

O'Neill-Brown's seminal paper [38] on culturally adaptive agents sparked a lively debate on how robotic design should be considered based on the culture, or cultures, that it was created for [39-41]. Particularly, the author posited that our verbal and nonverbal communication styles reflected our culture, and as such, cultural variables should be factored into agent design for optimal communication. As is shown in the later sections, her call for social agents that can detect culturally varying communication cues and display appropriate responses has motivated much of the current body of research. O'Neill-Brown's framework [38] was predicated on an underlying assumption that culture causally influenced technology. In contrast, subsequent work has argued for a bidirectional and reciprocal interplay between culture and technology [42-44]. Šabanović's [45] theoretical piece on the positioning of robots in society further echoed this position, suggesting that social progress is made by society and technology mutually shaping one another.

In order to effectively communicate with a social agent, the agent's intentions and communication cues must be correctly interpreted by human interaction partners [46]. In today's increasingly multicultural and globalising world, the task of achieving such effective communication in a culturally sensitive manner (i.e., a manner that embraces and reflects cultural differences) remains a complex challenge. The cultural studies described here argue that in order for robots to develop human-like communication abilities, they must possess the essential capabilities as proposed by O'Neill-Brown [38].

To date, two national cultures (Japanese and American) in particular have frequently been the focus of experiments seeking to examine the effects of cultural differences in the way people perceive and engage with social robots. This focus stems from psychological research traditions that typically place American and Japanese cultures as squarely representative of Western and Eastern cultural norms respectively, and also, clear exemplars of cultures that typify individualistic and collectivist values as well [29]. However, cultural comparison requires far more nuanced analyses than simply examining what happens when individuals from two very different cultures interact with robots. Even within more 
localised clusters of Western cultures, such as Italy and the United Kingdom, markedly different preferences have been observed in terms of how individuals from each country might envision using a robot as a tool in their professional lives [47]. Thus, a critical overview of the state of the art in research examining overarching cultural differences, and the range of circumstances in which cultural specificities are observed, is needed in order to articulate and galvanise the impact and importance of culture on human-robot interactions.

\section{Literature Review}

\subsection{Cultural Influences on Knowledge of and Expectations Towards Robots}

Despite the nation's significant contribution to the development of social robotics, Japan's so-called "robot mania" [12] is in fact, far from established. Bartneck et al. have for example found on their measure of negative attitudes to robot (Negative Attitudes toward Robots Scale, NARS) that their Japanese participants were not particularly positive in their attitude to robots [48]. In a later study with larger sample [49], the authors compared cross-cultural samples representing seven countries of online community members for a robotic $\operatorname{dog}$ Aibo (Sony) with a control sample of university students matched for the nationalities of the Aibo community. While country groups were a significant factor, it was the US participants who reported the most pro-robot (i.e., lower) ratings on the NARS. Further, the cross-cultural community of Aibo owners reported more positive ratings than non-owners as a group over and above nationality or cultural group. Given that people's general exposure to robots, as well as actual interactions with robots, are much greater in Japan than the U.S., the finding reminds us that ownership and personal decisions such as purchasing a robot may mediate membership to a cultural group and its implied/associated exposure to robots more generally. The role of experience over exposure is reiterated in a French-Japanese study, where participants were asked about their attitude to robots before viewing a robot expressing either happy or sad emotions in movement [50]. While the Japanese participants rated both humans and robots as similarly unsafe, the French group felt safer about and warmer towards robots. Interestingly, this seemingly surprising finding (given that Japan is often thought of as the 'robot nation') [51], was in fact accounted for by the length of exposure; the longer a person was exposed to robots, the more positive their reported attitudes toward robots was, regardless of cultural group.

Haring et al. [20] found that their Japanese participants expressed similarly construed fears and views about robots to their European comparison group. In this study, Japanese participants differed from European participants on subtle but significant aspects of attitudes towards robots, such as readiness to deploy robots for childcare and their stronger fear for misuse of robots rather than robots themselves posing danger to us. Further, while Europeans and Japanese both indicated job loss to robots as a cause of concern, the Japanese sample saw it of societal rather than personal nature. This finding resonates with Bartneck et al.' reflection [49]. Specifically, these authors propose that Japanese people may have gained more realistic and balanced insights into the strengths as well as challenges of robots today through longer and greater exposure to robots from living in Japan. Japanese people have also been reported to have a heightened sensitivity to anthropomorphism, but this may be a by-product of higher exposure to robots in the Japanese people [52]. The increased propensity to see life among a broad variety of entities among Japanese individuals is implied in yet another recent study, where an operational failure was enacted by a robot when it approached one of the actors too close thereby losing its mobility. While the U.S. and Australian participants suggested giving the robot another command to resolve the situation, Japanese participants expected the task to be for a technician [53]. While a range of interpretations may be possible of this curious finding, extended exposure to robots among Japanese people may have equipped them with more realistic expectations of the robot's capacity as well as its limits today. Further, past research suggest that compared to children, adults are more resistant to perceiving robots as social agents during their interactions, possibly as a result of more familiarity or exposure to robotics in their environment $[54,55]$. Culture can thus provide individuals with varying levels of exposure to robotics, which in turn affects individuals' perceptions of robots' sociality. While the lack of measures on participants' robotic experience in the study by Bajones et al. [53] leaves us to merely speculate on the underlying reasons at this stage, this work opens up a potential avenue for future research.

Our imagination of life with robots and an embodied interaction with one may well show important differences across cultures. Shiomi and Hagita [56] found that groups of US and Japanese childcare professionals both felt skeptical about robot deployment in their childcare centres. However, the generalizability of these sentiments was questioned by the live usability component of this study with Japanese parents of toddlers, who elicited enthusiastic views about small robots roaming in their children's nurseries, even among those parents whose children appeared uneasy of the robots. Japanese media often critiques its country for lagging behind the West on family-friendly work culture as the country's tradition relies on mothers to be full-time, stay-at-home parents. The study offers interesting and potentially important implications for future childcare systems, where robotic childcare assistants might provide a unique solution to support working parents and their families. 
Similar to Japan, Korea also has a reputation for being open to robots, in particular to service robots. Over a decade ago [57], Korea was reported to be aiming towards having a robot in every household by 2020 . In cross-cultural studies, Koreans appear to be generally receptive towards robots as part of society [58]. For example, a study examining the use of robots for educational applications placed Korean parents at the top of the list for readiness to employ tutoring robots for their children, over Japanese and Spanish parents [14]. Yet, like the example of Japan, greater knowledge and exposure to robots among Koreans do not necessarily result in more positive attitudes towards robots [59]. Findings here, mostly via questionnaires, seem to be somewhat discordant with an interview study suggesting people's fears of robots are often vague and stem from uncertainty, which implies that simple exposure may be an effective method for resolution of such fears [60]. With that being said, it is plausible (and remains to be tested) that further exposure to robots could give rise to new or greater uncertainties in the user's mind, or indeed, a better understanding of robots' limited capabilities.

These apparently discordant results also remind us that one's cultural group is perhaps best understood as one of many variables that shapes how we interact with robots. For example, one may identify with a cultural group and yet the sense of membership may be overridden by other demographic (such as age, sex, occupation, etc.) or experiential factors $[49,50]$. Evidence suggests that a person's age, gender, height, attitudes to robots, and even pet ownership all influence how we perceive robots [61]. These findings further resonate with studies that show acceptance of robots is optimized when the postulated 'personality' of the robot is matched to the job at hand [62]. The picture is further limited then to tasks requiring acute perception and service for people [63] rather than those involving creativity, diplomacy or emotional labor [64].

Together, these findings suggest that the role of attitudes and expectations for robots are complex. A recent survey study further showed that while the EU nationals were similarly ambivalent about deploying robots for care of elderly individuals, younger or educated and urban-living male participants showed a trend to being more receptive to robots taking on such a role in the future [65]. It would be important to articulate whether some of the complexities seen in the literature may be a by-product of disparities in the methodologies. This issue is revisited below in the Discussion section.

\subsubsection{The Role Played by Cultural Values and Communication Styles During HRI}

It has been proposed that more in-depth analyses of cognition and emotion may help unpack the highly complex literature reviewed above [38]. A recent example of research attempting to do this includes an online study comparing American and Kazakhstani participant samples, which examined which elements of Hofstede's model may give rise to culturally based expectations and attitudes during HRI [66]. Values expected to be culturally significant for Kazakhstani participants, such as power and masculinity (i.e., robots to be adult-aged and male), were not considered important by the U.S. respondents. Li et al. [58] examined another dimension from Hofstede's model, communication style, where the general consensus is that Western cultures are associated more with directness with lower reliance on mutual knowledge and context than Eastern and Asian cultures. In a live interaction with robots with varying degrees of anthropomorphic features, it was found that their Asian sample valued 'Asian' communication styles as implied by their higher ratings of responsivity, likeability, engagement, trust and satisfaction during socially complex settings such as teaching or being a tour guide [58]. In contrast, such aspects were not valued as much by the German participant sample in this study, which the authors attributed in part to a stronger sense of masculinity in Germany culture, as well as greater exposure to industrial robots in the country. The findings are also echoed in a design generating workshop [67] with Korean and US participants who were invited to create drawings of their ideal robots [68]. Korean volunteers imagined their robots to be human-like and their role as a social company; while the US participants envisioned theirs to be much more machine-like and as an extension of their household appliances.

Our cultural values have been found to be reflected in our perception and acceptance of robots around politeness when delivering a negative message, such as "I don't know" either directly or softened with a politeness marker such as an apology (i.e., "I am sorry but I don't know"). Salem et al. [69] found that their Arabic-speaking sample not only preferred a robot when it used a politeness marker, but this sample also rated such a robot higher on measures of warmth and closeness, even accepting it as an in-group member, compared to their English-speaking, but otherwise fellow Qatari participants. Interestingly, the control probes used in this study showed that politeness appeared to blur the accuracy of participants' recall, the classic phenomenon postulated in politeness theory [70]. While their findings are valuable and impactful both academically and for robotic design, the agent deployed in the study was a torso-only mannequin with a screen held for its head. It would be valuable for this work to be replicated using an embodied or humanoid robot to further understand the implications of culture in perceiving politeness for human-robot interactions with different types of robotic agents.

The studies reviewed here consider cross-cultural data on perception, cognition and emotion to reveal a phenomenological trend showing that robots who communicate in a manner aligned with our cultural practices, or speak in our native lan- 
guage, are more likely to be accepted as in-group members, as one of us. Additionally, while greater exposure appears to not necessarily elicit more confidence or positive attitude towards robots, those countries with longer and higher exposure to robots generally report a more insightful or realistic, views of robots. However, as we consider next, the influence of such past experiences of engaging with a robot within one's culture may be reduced depending on the circumstances of the interaction itself.

\subsection{Viewing Perception, Attitudes, and Behaviour Towards Robots Through a Cultural Lens}

Whilst preconceived expectations might serve as a predictor of how individuals will interact with and perceive robotic agents, the interaction itself can also modify subsequent perceptions and interactions with the robot. Preconceived expectations towards social robotic agents can change as a result of interacting with them. In this section, we highlight studies that examine how cultural differences affect the way individuals perceive and respond to the robot as a result of an interaction. Particularly, studies identified for our review suggest that existing research examining crosscultural differences in response to social robotic interactions are largely concentrated in three areas - first impressions towards the robot, responses to specific robotic design features, and responses to the robot's functionality.

\subsubsection{First Impressions Towards the Robot}

Generally, studies involving real-world interactions between humans and social robots indicate clear cross-cultural differences in the perceptions, attitudes, and behaviours between Eastern and Western cultures. Even from first impressions of viewing static images of social robots, Americans indicated higher ratings of likeability for the robots than the Japanese [23]. Further, a study examining the change in perception of social robots after an interaction showed that Australians had more positive perceptions of a Japanese female robot than the Japanese, and perceived the female robot as being more anthropomorphic [71]. However, preferences for robots are more nuanced than overall likeability ratings when comparing between cultures. For instance, in Bartneck's [23] study, whilst a main effect of culture shaped positive perceptions overall, a strong interaction was found between the participant's culture and the type of robot that they preferred. Americans indicated a higher preference for highly anthropomorphic androids and a lower preference for conventional robots than the Japanese. Similarly, Shinozawa et al. [72] found that Americans preferred three-dimensional robotic agents over two-dimensional on-screen agents, but reverse patterns of preference were observed for Japanese participants. This suggests that on top of broad cultural differences observed between Eastern and Western cultures, there are also nuanced preferences in the physicality of the robotic agent [73].

Evers, Maldonado, Brodecki, and Hinds [74] sought to compare the self-construal focus between Americans (relational self-construal) and Chinese (group self-construal) populations as to how it may relate to their willingness to trust and comply with a robot assistant and a human assistant. Here, American participants reported that they trusted and would comply with both types of assistants much more than Chinese participants. This indicated more positive attitudes overall in the US sample. When the assistants were manipulated as being an ingroup member in the scenario, Chinese participants became more comfortable with both types of assistants. Additionally, Chinese participants perceived more control over both assistants, and rated the robot assistant to be more anthropomorphic than American participants. However, when it came to considering instances of failure by a robot assistant, Bajones et al. [53] found no apparent cross-cultural differences on whether help should be rendered to the robot or not in situations of failure.

Aside from the binary distinction of differences between the East and the West, several studies have sought to examine cultures from other countries. Notably, Arabic cultures have been investigated to add further insight into the specificity of cultural variation during a HRI. Two such studies recruited highly international samples in the United Arab Emirates, where the first was conducted in a large shopping mall [75] and the second at a technology exhibition [76]. Riek et al. [75] found that the Gulf region (Iran, Iraq, Oman, Qatar, Saudi Arabia, United Arab Emirates, and Yemen) indicated more positive perceptions upon interacting with an "Arabic" robot than participants from African regions (Egypt, Tunisia, Libya, and Sudan). However, in support of previous findings [23], Mavridis et al. [76] found that this preference varied by the context of imagined future engagements with the Arabic robot. For example, within a medical context where a humanoid robot would provide treatment, only Southeast Asians had a positive attitude, whilst those from the Sham countries indicated a neutral reaction and all other countries including the Gulf, African, and Western participants had more negative attitudes. Western participants had the highest agreement amongst the other groups when it came to the opinion that their children would enjoy learning from the Arabic robot that they had just interacted with.

Studies have also shown that generalised effects of group dynamics during HRI might emerge as a function of belonging to a more individualistic or collectivistic culture. For example, Fraune, Kawakami, Šabanović, de Silva, and Okada [77] found a generic preference across cultures for interacting with a group of robots compared to a single robot at a time. Interestingly, Japanese (i.e., collectivistic) participants indicated a higher likeability when interacting with the group of 
robots than American (i.e., individualistic) participants, suggesting that our perception of robots may be influenced by our cultural preference for group or individual interaction. Even when a group consisted of two humans and one robot, this finding remained consistent [74, 75], where Japanese participants rated the robot they interacted with higher levels of animacy, intelligence, and feelings of safety as compared to Australians. Further, Haring et al. [78, 79] explored how the participant's role in the group would moderate the effects of culture. They found that Japanese participants who were passive observers of the group interaction as compared to active interactants in the group, rated the robot to be higher in anthropomorphism, animacy, intelligence, and safety. On the flip side, another study examined the influence of culture in evaluating how appropriate a robot is in spatially positioning itself in relation to a group of individuals [80]. Here, Chinese participants, another collectivistic cultural group, appeared to prefer stimuli images of robots that were positioned closer to a group of humans, than American and Argentinian participants.

In sum, despite the overall finding that Westerners appear to perceive social robots more positively than Easterners after interacting with them, there are more complex nuances to subjective preferences that play a critical role in appreciating the differences between cultures. Next, we delve more deeply into studies that examine cultural differences in how individuals respond to specific verbal and nonverbal interaction cues of the robot.

\subsubsection{Responses To Specific Robotic Design Features}

Cultural differences in communication style are ubiquitous and enduring. Two studies sought to examine the influence of culture in the individual's preference for a specific robot communication style [39, 81]. In Rau et al. [81], Chinese participants preferred an implicit communication style compared to German participants, and evaluated the robots as being more likable, trustworthy, and credible. Further, Chinese participants were also more likely than the German participants in accepting the implicit recommendations. In Andrist et al. [39], Arab participants were more likely than American participants to comply with recommendations from robots with high rhetoric ability. Additionally, an interaction effect was found in terms of American's preferences, where they were more likely than Arabs to comply with robots that indicated high knowledge and had low rhetoric ability. Ironically, Americans on the whole rated the robots to be more credible and sociable than Arabic participants. These studies are indicative of cultural differences in interpreting specific communication styles and reaffirm O'Neill-Brown's proposal [38] that social agents should be designed to match their user's communication preferences to optimise the social interaction.
Culture also affects how we produce and interpret nonverbal cues such as symbols and gestures [82]. This is important to consider as some researchers estimate that $60-65 \%$ of social meaning is derived from non-verbal behaviour [83]. In one study by Trovato et al. [84], the robot's ability to express emotions through its facial features was evaluated. As intrinsic cultural differences were suggested to affect our interactions with a robot, one way to adapt the robotic agent to specific cultural contexts was to localise the robot's facial features as a means of enhancing the interaction process. Here, Trovato et al. [84] suggest that there is an underlying difference in the type of symbols different cultures rely on to recognise emotion in the facial features of social robots. They found that localisation of Western and Japanese facial features increased the recognition ability of each culture-i.e. Westerners had the highest recognition rate amongst other cultures when asked to label emotional expressions presented in the Western facial feature set, while Asians had the highest recognition rate amongst other cultures when asked to label emotional expressions presented in the Asian facial feature set. Egyptians were also recruited in this study, and their preferences were similar to Asian participants. Additionally, when prompted to express preferences between expressions that were affixed with or without Japanese comic symbols, Asian and Egyptian participants preferred the use of these symbols more than Western participants. Taking these findings altogether, this suggests that there are relative sensitivities by culture for interpreting emotion, as well as cultural differences in the willingness to use additional symbols to aid emotion recognition.

Aside from differences observed in rather extreme ends of the culture, studies also sought to show differences within similar cultures towards the perception of nonverbal interaction cues. Suzuki et al. [85] found an activation of the primary motor cortex whilst a Japanese, but not a Chinese participant, watched a robot gesture and greet in a Japanese the style. Within the remit of a single case study, it nevertheless suggests that culturally sensitive perceptions can be evidenced at neuronal level, and that our brains develop cultural specificity according to our cultural identity, which can be dissociated from other cultures. The cultural difference within Western cultures around nonverbal cues were further supported by Eimler et al. [86], where they examined how German and American individuals attributed emotion to varying ear positions of a robotic rabbit. Whilst both cultures displayed highly similar levels in emotion recognition for various ear positions of the rabbit robot, differences in the categorisation of emotions were found using a range of labels. Using factor analyses, responses by German participants yielded three factors (Positive Evaluation, Embarrassment, and Hostility), whilst American participants yielded two factors (Positive Affect and Negative Affect), suggesting there are subtle nuances in categorisations of emotions perceived 
through nonverbal cues between these cultures. Destephe et al. [50] examined the cultural differences between French and Japanese participants in their ability to attribute emotions toward a walking humanoid robot. Both cultures displayed highly similar levels of emotion recognition, but the French participants rated feeling warmer toward the robots than the Japanese participants. Again, this suggests that cultural differences do not necessarily follow the archetypal pattern.

\subsubsection{Responses to Robot Functionality}

In this section, we examine cultural differences in how humans respond to robots that are designed to be socially assistive. First, we establish where the cultural differences lie in general preferences after actively interacting with social robots that are designed to be socially assistive. Then, we look more specifically at studies that examine cross-cultural differences, this time, spanning more broadly than so far in the paper across lifespan. In doing so, our aim is to consider the specific needs and requirements that may arise for a broad range of end users of social robots, as well as the roles culture plays across human development.

Culture can affect the way we determine which qualities might be desirable for certain social roles. In a study examining the therapeutic effects of Paro, a seal robot, cultural differences were found in the participants' range of positive impressions garnered from the interaction [87]. Whilst Western participants highly evaluated Paro for its comfortgiving features and comparability to interacting with a real animal, Eastern participants saw values in Paro for its ability to induce a favourable impression and encourage continued interactions. This suggests that cultural differences may be reflected in the range of qualities that we value in social robots. Cultural variations were also found in the willingness in future practitioners planning to use robots. Conti et al. [47] compared two European groups of psychology students, one from the United Kingdom and other Italy. Compared to the Italian students, British students were less willing to use socially assistive robots in their future work, despite indicating higher levels of trust for these agents. Further, British students reported negative impressions of the robot, whilst the Italian students reported more positive impressions. The data demonstrate that valance of robot perception does not necessarily relate to whether the robot is trusted, nor is it necessarily useful for predicting future intentions to deploy that robot.

Studies with vulnerable populations, such as children, older adults or those with additional needs, highlight the importance of examining the level of engagement and expressiveness of users in order to achieve successful implementation. A study in the context of occupational therapy for autism suggests that Japanese children with autism were more engaged with a socially assistive robot than autistic
Serbian children [88]. The higher level of engagement by Eastern children with a social robot is supported by examining typically developing children [89], where Pakistani children were more expressive than Dutch children, and preferred to engage a robot in their play over playing alone. Additionally, the finding of lesser expressivity exhibited by Dutch children [89] was echoed in a study examining children's interactions with a social robot in a diabetes camp [90]. These authors found that Dutch children were not as expressive or open as Italian children were during gameplay with the social robot Nao (Aldebaran/Softbank). Taken together, these studies highlight not only how mental and broader health needs are intricately related, and shape HRIs, but also that culture may play an important role in further mediating the human-robot relationship.

Research with elderly individuals suggests that culture casts a shadow on our willingness to invite social robots into daily life in the later years. Through simulation of real-world scenarios of challenges that the elderly might encounter, Torta et al. [91] found no cultural differences between the ratings given by Austrian and Israeli elderly individuals on their acceptance of such robots. With another sample of elderly individuals, Cortellessa et al. [92] found that Swedes were less intimidated by the prospect of introducing robots in their homes than Italians. Further, Swedes appeared to be more interpersonally driven and had concerns about their privacy violation. Whilst more research is needed to replicate these findings, and establish how consistent they are across different cultural samples, it is also important to acknowledge the potential of cohort effects in these studies, as elderly individuals will, as a rule, have spent a smaller portion of their lives interacting with technology compared to younger adults and children. Research examining cultural impacts on HRI therefore must maintain sensitivity to differences arising from cross-generational exposure to technologies, in order to understand the needs of the elderly population as users of social robots in specific cultural contexts.

Within this section, we sought to synthesise studies that examined the responses of humans who interacted with a social robot. Not only were there cultural differences to how individuals perceived social robots after an interaction, but there were specific response variances to specific verbal and nonverbal communication cues exhibited by the social robot. Additionally, a body of studies also sought to evaluate and found differences in the responses and attitudes of children when robots were implemented as socially assistive tools for them. Scant research, however, has focused specifically on cross-cultural differences among elderly users of social robots. 


\subsection{Exploring Culturally-Specific Robotic Designs}

When surveying the available literature on the role played by culture during HRI, a final aspect that warrants consideration is the extent to which culturally-specific (or culturally-informed) robotic design improves the human user's experience. In this context, most work has focused on people's responses to an individual robot that has been programmed to reflect cultural norms from a specific culture. Much of this work is predicated on the notion of greater homophily (or similarity between self and other) sparking and sustaining social relationships, as has been written about extensively by sociologists (e.g., [93, 94]). Indeed, this idea also forms the foundation for an influential theory from developmental psychology of how children learn about their world and develop social relationships (the so-called "like me" hypothesis; [95]). Over the past several years, a number of studies have begun to explore the extent to which changing robots' behaviour or appearance to more closely align with cultural expectations or norms positively benefits HRI, and reveal mixed evidence for the efficacy of such manipulations.

Early studies in this area set the stage for how designers and developers might implement culturally-specific features to robotic systems. In one of the first studies to explore these issues, Wang et al. [96] examined the extent to which university students from China and the USA would follow a robot's recommendation, depending on whether the robot's communication style (implicit vs. explicit) was culturally normative to the students' background. The authors found evidence that, indeed, participants are more likely to heed a robot's advice if it is presented in a culturally-normative way (implicit for Chinese students, and explicit for American students). However, the authors also reported a somewhat unexpected finding that Chinese students reported more negative attitudes toward robots overall, and were also less likely to heed the robot's advice no matter what their communication style. This study thus highlights the fact that designing robots that appear to display cultural homophily is not a guarantee of human user acceptance, as well as the need to balance a culturallysensitive design/functionality of a robot with variations in the attitudes participants have toward robots (that are possibly immune to design tweaks) that differ across cultures.

Research on the impact of robot design in engaging people in the Middle East includes work discussed in the previous section by Riek et al. [75] and Mavridis et al. [76], suggests that an Arabic-speaking humanoid robot modelled after Ibn Sina (a well-respected Islamic philosopher, doctor, and polymath who lived between 980-1037AD) was viewed more favourably by passers-by from a more similar background to the real Ibn Sina (i.e., from Gulf states as compared to African countries). This robot was generally well-received by public audiences when set up in shopping malls in the UAE [75] and Dubai [76]. Moreover, regional and educational differences emerged in people's acceptance of this robot, with passers-by from the Gulf region viewing the robot more favourably than passers-by from Africa (suggesting some degree of cultural homophily), and people without college degrees viewing the robot more favourably than people with college degrees. Subsequent work directly compared a sample of Egyptian and Japanese participants who engaged in simulated video conferences with robots that greeted and spoke with them in either Arabic or Japanese [97]. The authors assessed participant preferences for the culturally familiar versus unfamiliar robot, and found that the Egyptian participants preferred the robot that spoke Arabic and greeted them according to Egyptian customs, while the Japanese participants preferred the robot that spoke Japanese and greeted them according to Japanese customs. When further surveyed about their expressed preferences, the biggest reasons participants reported preferring the culturally similar robot over the culturally distant robot were a sense of familiarity (27\%), understandability (26\%), non-verbal communication (18\%) and language (16\%). What this study highlights is that while the language a robot speaks is important, culturally-specific non-verbal aspects of a robot's behaviour are every bit, if not more, important in shaping users' preferences and comfort with robots.

This theme is further explored in a paper by Makatchev et al. [98], who sought to define how best to select and evaluate culturally salient behaviours among a small group of Arabic native speakers and American English native speakers based in Doha. As with the previous study, the authors explored the impact of both verbal and non-verbal behaviours, and their particular robot (Hala robot receptionist hardware) featured a human-like stationary torso with an LCD mounted as the head, which allows for experimenters to easily manipulate the human- or machine-like appearance of the head and face. For this study, the face ranged from looking like a native speaker of Arabic or a native speaker of American English to looking more like a cyborg/mechanical robot. The authors also programmed the robot to speak and non-verbally respond according to more Arabic or American English conventions for greetings, directions, disagreement and handling failure. In brief, the authors did not find evidence for ethnic (or cultural) homophily, but nonetheless call for future research efforts to work even harder to match robot attributes to human users.

A subsequent study attempted to do this by examining a different aspect of non-verbal behaviour: namely, interpersonal distance between a robot and human [99]. The authors of this study recruited groups of German and Arab participants, who score high on dimensions of individualism and collectivism, respectively (according to Hofstede's Individualism dimension), which influences preferences for comfortable proximity to others. Moreover, these two groups of participants are also categorised as low-contact (Ger- 
mans) and high-contact (Arabs) according to Hall's cultural dichotomy, which has also been shown to shape individuals' preferences for proximity to another person. In the first experiment, Eresha et al. first asked participants from both cultural backgrounds to place two robots the ideal distance apart so they could have an (imaginary) conversation with each other, and in a separate condition, asked participants to position the robots and themselves appropriately so that all three could have an imaginary conversation. As predicted, the Arab participants positioned the robots closer to each other and to themselves in this scenario than the German participants. In the second experiment, the authors positioned the robots, and German and Arab participants according to the interpersonal distances preferred by the two different groups in the first experiment. This meant both German and Arab participants experienced short conversational interactions with robots who were positioned in both the ideal German and Arab interpersonal distances. Participants then rated the robots on a number of subjective measures about how positively they felt toward the robots. Contrary to the authors' predictions, they found no strong evidence in this second experiment, where robots' proximity to human participants is dynamically modulated, that preferred interpersonal distance reflected cultural norms. A major limitation of this study (and indeed, many studies in this field, when we look to draw meaningful conclusions) is the small sample size and the fact that the same people participated in both experiments. As such, individual differences and personal preferences could have an outsize influence on the findings, thus complicating what we can conclude about cultural homophily and proximity between people and robots during social interactions.

While the idea of human users preferring robots that are most similar to themselves is one that is discussed at length in many of these studies, the evidence shows the relationship between similarity between self and a robot other, and acceptability, is far more nuanced and complex than simple homophily arguments might suggest. A recent study by Trovato et al. [100] featured a clever manipulation to examine notions of relative cultural distance that further illuminates this issue. Specifically, these authors used a similar video conference paradigm to one used by their group previously [97], with conferencing partners falling into a two by two factorial design, with factors culture/language (German vs. Japanese) and agent (human vs. robot). The interesting and innovative twist the authors introduced is to test not German or Japanese participants, but Dutch participants. The thinking here is that if cultural similarity drives acceptance and positive attitudes towards robots, then Dutch participants should find the German robot more familiar (and thus more acceptable) than the Japanese robot (with the human video conference partners being included as control conditions). This is precisely what the authors reported: the Dutch participants expressed a strong preference for the German robot over the Japanese robot, with leading reasons for their decision including comprehensibility (46\%), sense of familiarity (27\%), and non-verbal communication (18\%). Therefore, we can see that cultural homophily or the extent to which a robot is "like me" is not an all or nothing feature, and relative cultural similarity can smooth social interactions and shape preferences in some situations.

While interest continues to grow in creating or programming robots' appearance, verbal and non-verbal behaviour to align in culturally consistent ways with human users, this area remains in its infancy. The work reviewed in this section demonstrates that in some situations, cultural homophily clearly shapes human user preferences. More recent work has, demonstrated that simply introducing a robot as being made in a particular country may evoke the national stereotype of that country, and can consequently impact perceptions of the robot's competence and warmth [101]. However, as many of these studies also demonstrate, this relationship is neither straightforward nor linear, and individual differences and personal preferences have a strong influence as well. An important area for future development will be to move beyond simply designing individual robots to reflect specific cultural norms or preferences (so-called culturally specific robots), and instead work to develop robots that are culturally adaptive, for example, by making slight adjustments in body language, spoken language, proxemics and other behaviours based on the user or user group. Currently, understanding the role played by perceived cultural similarity between robots and human users remains an extremely relevant and underexplored area of research that will yield important new insights for improving human-robot interaction in future years.

\section{Discussion}

\subsection{A Role for Culture in Shaping the Next Generation of Social Robotics}

This review aimed to reveal how cross-cultural differences affect the way we perceive and behave in human-robotic interactions. We highlighted the complexities in which different national cultures influence the ways in which we have preconceived expectations and attitudes towards social robots and the way we respond to them during an interaction. Further, we also highlighted how we respond to cues displayed by social robots that are thought to be specific to our individual cultures. Overall, it appears that a robot that displays cultural sensitivity promotes human acceptance $[69,81]$. It echoes other studies reporting that we are more likely to anthropomorphize robots with whom we share some aspects of our identity [102].

Technology has evolved over centuries from powering lifeless props to the increasingly sophisticated autonomous 
actors we are now welcoming into our social world. Through our analysis using a cultural lens, we have highlighted how social robots are perceived and used by individuals from a variety of cultural backgrounds. Via the individual sections of this review, we make the following argument: if these agents are presented universally, individuals will vary in their reports of maximum utility and enjoyment of such technology, as a function of cultural background. As such, designers and developers of robotics will benefit from considering the cultural foundations that shape users' perceptions and preferences for specific interaction cues. In addition, how robots that can adapt to, or reflect, cultural norms may serve to further enhance human-robot interactions.

Yet, as relevant and powerful as culturally-aligned cues and behaviours are for facilitating interactions, it is equally important to note that people are adept at compromising and learning to interact with others despite sometimes vast cultural differences. Whilst the development of robots that exhibit and adhere to cultural norms is still nascent, it is also important to question the extent to which it is necessary for robots to be culturally adaptive or reflective to ensure successful interactions with human users, since people already adapt and will continue to do so to social cues exhibited by robots. Potentially, it may not be necessary for robots to be programmed in culturally-specific manners for general social interactions (such as assisting with performing a physical task), as humans learn to interpret social cues displayed by others over time and will likely learn to do so with robots as well, and especially those robots with whom they come into frequent contact. What remains a critical question, and one that the academic/research community is ideally positioned to address, is whether certain social exchange scenarios exist in which cultural alignment is vital. Further, recent reports in the media, as well as empirical research, have highlighted the dangers of using the capabilities of artificial intelligence to recognise and single out individuals based on gender, race, and sexual orientation [103, 104]. The intentions underpinning the use of such robots would thus also need to be taken into account, to examine ethical concerns pertaining to culturally aligned robots, and ensuring these agents are designed to help rather than harm target users.

\subsection{Limitations}

Articulating and prioritising clear directions for future research in this domain are complicated by disparate and sometimes conflicting findings in the literature [20], even within the same cultural group(s). We also see a general lack of consensus as to how best to study our expectations and attitudes during our interaction with robots. In the following we consider key issues identified for future research to tackle.

The studies reviewed here report using a wide range of survey methods and experimental designs. Given that the primary focus of most of these studies was to examine the main effect of culture, a between-subject design may have been optimal; instead, a mixture of correlational or a repeated measures design have been deployed and not necessarily with justification. Further, study sample sizes varied widely between 1 and 27,000 participants (see Fig. 1), with demographics including the general public, online technology communities [21], or robot enthusiasts [49]. Variations in sample size (especially those with small sample sizes) and demographics, as well as inconsistent statistical methods, all complicate what we can generalise from any one study, as well as obscure directions for future work. Additionally, a diverse range of robotic agents have been deployed with varying degrees of anthropomorphic, or human-like features, as has previously been pointed out [105, 122]. Though research across a large (and ever expanding) range of robotic platforms is certainly needed, the often-significant differences in the size, shape and behavioural/linguistic repertoire of robotic agents studied here also raise significant challenges for generalisability. While future meta-analyses, as well as checks for publication bias, will ultimately add further clarity in terms of how robust, reliable, and replicable the effects of culture on human-robot interaction are, the lack of sufficiently consistent measures and analytic methods present significant roadblocks for generating more empirical synthesis of extant findings at present. We remain hopeful, however, that increases in transparency and rigour in behavioural research practices [106, 107], as well as more laboratories sharing their research data on open science repositories [108], will increase the viability of this option in the near future.

\subsection{Future Perspectives On Developing Culturally-Attuned Robots}

The bodies of literature synthesized in the present paper clearly point to a potentially significant role for culture shaping people's interactions with social robots. Marked variations in methodologies may be critiqued as confounds, but they also reflect the wide range of robotic agents available today which can be used as a scope for further research. We call for future studies to aim for more systematic and robust replications to confirm, validate and to build on the current body of evidence on the role of culture during HRI. It would involve more tightly controlled experiments, and sound justifications for decisions around study designs and powers in published studies. Much broader and more comprehensive inclusion of cultural samples are also needed to even out the relative over- (e.g., Japan and USA) and under-representation of some countries and to investigate beyond the West/European-East/Asian dichotomy. Our synthesis has also illuminated that the vast majority of our current knowledge about culture and HRI rely on neuro-typical adult populations. While this is a good start, the literature is in 
much need of broadening to other adult population groups as well as across the developmental trajectory, in order to understand how a broader range of human needs and interests may interact with our cultural backgrounds, and how they may in turn impact on the quality of interaction with robotic agents. To this end, further efforts for multi-disciplinary work with neighbouring fields such as developmental robotics [109] may bring unique benefits in studying human development alongside robotics.

Recent evidence shows that a number of elements influence our actions, cognition and emotions during HRIs. These include the motivational factors underpinning an interaction with a robot, such as a sense of commitment to a robot by the user [110], or our perception of robots making an effort during interaction [111]. An important avenue for future research will be to explore more deeply whether elements that drive our motivation to engage with a robot are related to our cognitive styles and culturally derived preferences. Such insights would provide valuable contributions to the future design and development of robotics as well as stimulating a significant paradigm shift in the robotics research.

Another area where future research efforts would be valuable is to incorporate longitudinal research designs, which can generate particularly important insights into how people's attitudes toward and acceptance of robots as a result of their cultural background change across time or development. One valuable avenue for the future of cross-cultural HRI research would be to join forces with existing longitudinal studies [119] and those spanning across human development [120] on the long-term trajectories of experience and relationship with robots. For example, would certain cultures be more flexible or learn to develop positive perceptions and attitudes faster than other cultures? And, might individuals from certain cultural backgrounds be more flexible or quicker to develop positive perceptions and attitudes compared to individuals from other cultures? Alternatively, might other cultural backgrounds make it very challenging for people to ever accept robots in socially assistive roles? Returning to Heyes' cognitive gadgets hypothesis $[5,6]$ introduced at the beginning of this piece, the role of one's social culture in supercharging our ability to learn, innovate and reason is unparalleled across the animal kingdom. This flexibility and creativity in cognition suggests that human behavior toward, and social interactions with, robots are hardly static or fixed, and the longer we spend with robots, the more our attitudes and behaviors toward them might evolve. For example, a recent study by Cross et al. [112] sought to map behavioral and brain-based responses of participants' empathy toward robots before and after a prolonged socializing intervention wherein participants took home a palm-sized Cozmo robot and played games with it each day across a five-day period. While this study did not find compelling evidence that spending more time socializing with a robot shaped empathic responses toward that robot, it nonetheless raises many interesting questions regarding what the boundary conditions are for shaping our social perceptions of and behaviors toward robots, as well as role of culture in relationship building with robots.

Further, it is essential to investigate under what conditions could critically benefit from culturally sensitive robots. Studying across cultural practices and learning from broader literature on social anthropology, sociology, ethnography or human-computer interaction would provide exemplars to identify and point to priority areas for future research on social robotics and robotic design. In doing so, the process needs to be closely grounded with today's remit of robotic capacities. Many robots today may appear to hold conversations with humans and handle simple gestures or manage some form of emotion expressions. In reality, the speech and behaviour are controlled by on-site and live programming by humans and unnatural gaps and delays are common. Many lack major human body parts including limbs or fingers. Many are not capable of bipedal walking and movements leave margin for considerable improvement. Thus, the experience of technical failures during an interaction is common. However, such failures have been suggested to strongly influence people's perceptions and feelings towards robots [113, 114]. In such situations, if a robot can be programmed to display culturally sensitive cues, this may help to buffer against human users developing negative perceptions of the robot. In order to explore the possible benefits that subtle changes in culturally aligned robot programming might induce among human users, deeper collaboration between engineers, social robotics, psychologists and sociologists will be vital.

As robots become ever more sophisticated, ubiquitous, and continue to permeate our everyday life, an important agenda for future studies will be to test the extent to which people reliably prefer robots that act, move, or look "like me" $[95,115]$. Such work would also enable clear testing of the descending portion of the much debated but speculative "uncanny valley" phenomenon [116]. These fundamental and complex questions transcend many of the surface features that are currently under examination. Such future endeavors will require careful articulation and investigation from a broad spectrum of thinkers from the sciences, arts, and humanities. Significant questions remain concerning our future visions for the place of robots in our society and our social cognition [117], which are clearly ripe for further exploration.

Robotic agents are created by humans and so far, robots across the spectrum, and perhaps most impressively, social robots, have shown significant development in their capabilities. It seems technologically viable to continue advancing robotic form and function to further facilitate human engagement. We sense that we are now nearing a junction for complex decision making. What do we envision for the future 
of socially-interactive robots? Would we strive for further sophistication of robots and for them to behave more like 'one of us', as if they are a member of a country or cultural group? Or would we rather that robots were designed and optimised for robots' sake? How do purposes, contexts and users influence the requirements for robotic agents? These questions should not be entirely left with those involved in robotic designs and programming, but also include contributions from sociologists, anthropologists, psychologists, philosophers, neuroscientists and artists as well. Inclusions of broader cultural practices and groups in the process will critically inform the range of user profiles and expectations as well as requirements for robotic behavior and functions.

Further, research could also examine how the cultural background of creators in the robotics industry affects preferences towards culturally-adaptive robots. At the end of the day, robots are created based on conceptions of their designers, programmers, and developers. As such, any robot's ability to reflect or be sensitive to cultural norms is necessarily limited by its creator's attributions, biases, and understanding of the culture of others. Future studies could either consider examining robotics creators' cultural (and disciplinary) backgrounds, or examine whether compatibility between the culture of the creator and the user matters in ensuring that social robotic cues are designed most optimally based on accurate and innate cultural knowledge of the creator.

Lastly, another possible avenue for future research could be to examine the impact of multicultural experiences on users' perception, emotion, and cognition during HRI. Whilst current research reviewed here focuses on the level of single cultures and assumes that participants identify with a single national culture, literature in cross-cultural psychology suggests that our world is becoming increasingly diverse, in part driven by migrations, resulting in the forging of increasingly multicultural identities [118]. What are the implications of cultural mixing and bridging, and a population that is becoming increasingly multilingual, multi-national, and multicultural on social cognition towards robotic agents? Future studies could consider including individuals who have migrated or lived abroad for a certain period of time (e.g. exchange students) to determine how experiences of being part of another culture, and cultural identity, shape users' perceptions and preferences for cues, features or functions of robotic agents.

\section{Conclusion}

Culture holds societies together through shared perceptions and practices. This review examined how rapidly developing advances in social robotics can be integrated into this narrative, by looking at our prior preconceptions and responses to these agents during interactions. Further, we presented insights as to whether such social robots should be designed for specific cultures in mind, or if they should be adaptive to multiple cultures, in order to support successful interactions with people. In his recent book titled "Who's Afraid of AI", technology writer Thomas Ramge proposes that "[c]ultural attitudes accelerate or slow down the acceptance of innovations. In Europe, robots are enemies, servants in America, colleagues in China, and friends in Japan" [121]. While the empirical work reviewed in this paper might not (yet) fully support to Ramge's thesis, the notion that culture so deeply permeates and shapes our relationship with all technology, and perhaps most strikingly, robots, is one that those of us working in social robotics ignore at our peril. In showing how cultural backgrounds influence our preferences for different robotic agents, right down to unitary verbal or non-verbal social cues, we have attempted to highlight how understanding the complexity of culture will help to understand what it means to be social actors on this global stage.

Acknowledgements We would like to thank Dougal Wright, Coco Ai Yasui, and Terrence Tibbs for their invaluable support and inspiration while writing, and Anna Henschel, whose keen scientific writing eye helped us further improve this piece.

Funding M.R. and E.S.C.'s contributions to this piece were supported by funding from the European Research Council (ERC) under the European Union's Horizon 2020 research and innovation programme (Grant agreement number 677270 to E.S.C.). E.S.C. is further supported by the Leverhulme Trust (PLP-2018-152).

\section{Compliance with Ethical Standards}

Conflict of interest The authors declare that they have no conflict of interest.

Ethical Approval As this paper summarises and reviews already published primary research, no new ethical approval was sought for the work presented here.

Open Access This article is licensed under a Creative Commons Attribution 4.0 International License, which permits use, sharing, adaptation, distribution and reproduction in any medium or format, as long as you give appropriate credit to the original author(s) and the source, provide a link to the Creative Commons licence, and indicate if changes were made. The images or other third party material in this article are included in the article's Creative Commons licence, unless indicated otherwise in a credit line to the material. If material is not included in the article's Creative Commons licence and your intended use is not permitted by statutory regulation or exceeds the permitted use, you will need to obtain permission directly from the copyright holder. To view a copy of this licence, visit http://creativecomm ons.org/licenses/by/4.0/.

\section{References}

1. Frith CD, Frith U (2007) Social cognition in humans. Curr Biol 17:R724-R732. https://doi.org/10.1016/j.cub.2007.05.068 
2. Gates B (2007) A robot in every home. Scientific American. https://www.cs.virginia.edu/ robins/A_Robot_in_Every_Home. pdf. Accessed 20 Feb 2020

3. Weinberg N (2019). Rbr report: how to start a robotics company. Robotic Business Review. https://www.roboticsbusinessreview. com/wp-content/uploads/2019/06/RBR-How-To-Start-ARobotics-Company-Final.pdf

4. Kacancioğlu E, Klug H, Alonzo SH (2012) The evolution of social interactions changes predictions about interacting phenotypes. Evolution 66:2056-2064. https://doi.org/10.1111/j.1558-5 646.2012.01585.x

5. Heyes C (2018) Cognitive gadgets: the cultural evolution of thinking. Belknap Press, Cambridge

6. Heyes C (2019) Précis of cognitive gadgets: the cultural evolution of thinking. Behav Brain Sci 42:e169. https://doi.org/10.1017/S0 140525X18002145

7. Atran S (1998) Folk biology and the anthropology of science: cognitive universals and cultural particulars. Behav Brain Sci 21:547-569. https://doi.org/10.1017/s0140525x98001277

8. Han S, Northoff G (2008) Cultural-sensitive neural substrates of human cognition: a transcultural neuroimaging approach. Nat Rev Neurosci 9:646-654. https://doi.org/10.1038/nrn2456

9. Papadopoulos I, Koulouglioti C (2018) The influence of culture on attitudes towards humanoid and animal-like robots: an integrative review. J Nurs Scholarsh 50:653-665. https://doi.org/10.1111/jnu. 12422

10. Zanatto D, Patacchiola M, Goslin J, Cangelosi A (2019) Investigating cooperation with robotic peers. PLoS ONE 14:e0225028. https://doi.org/10.1371/journal.pone.0225028

11. Kamide H, Mori M (2016) One being for two origins-a necessary awakening for the future of robotics. In: 2016 IEEE workshop on advanced robotics and its social impacts (ARSO). IEEE, Piscataway, NJ

12. MacDorman KF, Vasudevan SK, Ho C-C (2009) Does Japan really have robot mania? Comparing attitude by implicit and explicit measures. AI Soc 23:485-510. https://doi.org/10.1007/s00146-0 08-0181-2

13. Capek K (1921/2004) Rossum's universal robots (R.U.R.). Penguin, London

14. Han J, Hyun E, Kim M, Cho H, Kanda T, Nomura T (2009) Cross-cultural acceptance of tutoring robots with augmented reality services. Int J Digit Content Technol Appl 3:95-102. https:// doi.org/10.4156/jdcta.vol3.issue2.han

15. Whorf BL (1940) Science and linguistics. Technol Rev 42: 229-231, 247-248

16. Sapir E (1958) Culture, language and personality. University of California Press, Berkeley

17. Lufkin B (2020) What the world can learn from Japan's robots. BBC. https://www.bbc.com/worklife/article/20200205-what-theworld-can-learn-from-japans-robots

18. Fujiko F (1969) Doraemon series. Shogakkan (in Japanese)

19. Tezuka O (1959) Mighty atom/astro boy series. Kobunsha (in Japanese)

20. Haring KS, Mougenot C, Ono F, Watanabe K (2014) Cultural differences in perception and attitude towards robots. Int $\mathrm{J}$ Affect Eng 13:149-157. https://doi.org/10.5057/ijae.13.149

21. Nomura T, Tasaki T, Kanda T, Shiomi MH, Ishiguro H, Hagita N (2007) Questionnaire-based social research on opinions of Japanese visitors for communication robots at an exhibition. AI Soc 21:167-183

22. Nomura T, Syrdal DG, Dautenhahn K (2015) Difference on social acceptance of humanoid robots between Japan and the UK. In: Proceedings of the 4th international symposium on new frontiers in human-robot interaction. Canterbury, UK

23. Bartneck C (2008) Who likes androids more: Japanese or US Americans? In: 2008 the 17th IEEE international symposium on robot and human interactive communication (RO-MAN). IEEE, Piscataway, NJ

24. Iwamura Y, Shiomi M, Kanda T et al (2011) Do elderly people prefer a conversational humanoid as a shopping assistant partner in supermarkets? In: 2011 6th ACM/IEEE international conference on human-robot interaction (HRI). IEEE, Piscataway, NJ

25. Shiomi M, Iio T, Kamei K et al (2015) Effectiveness of social behaviors for autonomous wheelchair robot to support elderly people in Japan. PLoS ONE 10:e0128031. https://doi.org/10.137 1/journal.pone.0128031

26. Yu R, Hui E, Lee J et al (2015) Use of a therapeutic, socially assistive pet robot (PARO) in improving mood and stimulating social interaction and communication for people with dementia: study protocol for a randomized controlled trial. JMIR Res Protoc 4:e45. https://doi.org/10.2196/resprot.4189

27. Abe K, Pei Y, Zhang T et al (2015) Telepresence childcare robot for playing with children from a remote location. In: The International conference on advanced mechatronics (ICAM). https:// doi.org/10.1299/jsmeicam.2015.6.138

28. Gelfand MJ, Kashima Y (2016) Editorial overview: culture: advances in the science of culture and psychology. Curr Opin Psychol 8:iv-x. https://doi.org/10.1016/j.copsyc.2015.12.011

29. Markus HR, Kitayama S (1991) Culture and the self: implications for cognition, emotion, and motivation. Psychol Rev 98:224-253. https://doi.org/10.1037/0033-295X.98.2.224

30. Hofstede G (1980) Culture's consequences: international differences in work-related values. Sage, Beverly Hills

31. Brewer MB, Chen YR (2007) Where (who) are collectives in collectivism? Toward conceptual clarification of individualism and collectivism. Psychol Rev 114:133-151. https://doi.org/10.1037/ 0033-295X.114.1.133

32. Hui CH, Yee C (1994) The shortened individualism-collectivism scale: its relationship to demographic and work-related variables. J Res Pers 28:409-424. https://doi.org/10.1006/jrpe.1994.1029

33. Triandis HC, Bontempo R, Villareal MJ, Asai M, Lucca N (1988) Individualism and collectivism: cross-cultural perspectives on self-ingroup relationships. J Pers Soc Psychol 54:323-338. https:// doi.org/10.1037/0022-3514.54.2.323

34. De Mooij M, Hofstede G (2010) The Hofstede model: applications to global branding and advertising strategy and research. Int $\mathrm{J}$ Advert 29:85-110. https://doi.org/10.2501/S026504870920104X

35. Brewer MB, Gardner W (1996) Who is this "We"? Levels of collective identity and self representations. J Pers Soc Psychol 71:83-93. https://doi.org/10.1037/0022-3514.71.1.83

36. Oyserman D, Coon HM, Kemmelmeier M (2002) Rethinking individualism and collectivism: Evaluation of theoretical assumptions and meta-analyses. Psychol Bull 128:3-72. https://doi.org/10.10 37//0033-2909.128.1.3

37. Schimmack U, Oishi S, Diener E (2005) Individualism: a valid and important dimension of cultural differences between nations. Pers Soc Psychol Rev 9:17-31. https://doi.org/10.1207/s153279 57pspr0901_2

38. O'Neill-Brown P (1997) Setting the stage for the culturally adaptive agent. In: Proceedings of the 1997 AAAI fall symposium on socially intelligent agents.

39. Andrist S, Ziadee M, Boukaram H et al. (2015) Effects of culture on the credibility of robot speech: a comparison between English and Arabic. In: Proceedings of the tenth annual ACM/IEEE international conference on human-robot interaction. ACM

40. Bartneck C, Takahashi T, Katagiri Y (2004) Cross-cultural study of expressive avatars. In: Proceedings of the social intelligence design

41. Kido T (1998) Grand challenge problems on cross cultural communication-toward socially intelligent agents. In: Smith J (ed) Cooperative information agents II learning, mobility and electronic commerce for information discovery on the internet. CIA 
1998. Lecture notes in computer science, vol 1435. Springer, Berlin, pp 108-112

42. Beane M, Orlikowski WJ (2015) What difference does a robot make? The material enactment of distributed coordination. Organ Sci 26:1553-1573. https://doi.org/10.1287/orsc.2015.1004

43. Kaplan F (2004) Who is afraid of the humanoid? Investigating cultural differences in the acceptance of robots. Int J Hum Robot 1:1-16. https://doi.org/10.1142/S0219843604000289

44. Samani H, Saadatian E, Pang N et al (2013) Cultural robotics: the culture of robotics and robotics in culture. Int J Adv Robot Syst 10:1-10. https://doi.org/10.5772/57260

45. Šabanović S (2010) Robots in society, society in robots. Int J Soc Robot 2:439-450. https://doi.org/10.1007/s12369-010-0066-7

46. Fiore SM, Badler NL, Boloni L et al (2011) Human-robot teams collaborating socially, organizationally, and culturally. In: Proceedings of the human factors and ergonomics society annual meeting, vol 55. SAGE Publications, Los Angeles, pp 465-469

47. Conti D, Cattani A, Di Nuovo S, Di Nuovo A (2015) A crosscultural study of acceptance and use of robotics by future psychology practitioners. In: 2015 24th IEEE international symposium on robot and human interactive communication (RO-MAN). IEEE, Piscataway, $\mathrm{NJ}$

48. Bartneck C, Nomura T, Kanda $T$ et al (2005) A cross-cultural study on attitudes towards robots. In: Proceedings of the HCI international. Las Vegas, HCI

49. Bartneck C, Suzuki T, Kanda T, Nomura T (2006) The influence of people's culture and prior experiences with Aibo on their attitudes towards robots. AI Soc 21:217-230. https://doi.org/10.1007/s001 46-006-0052-7

50. Destephe M, Brandao M, Kishi T et al (2015) Walking in the uncanny valley: importance of the attractiveness on the acceptance of a robot as a working partner. Front Psychol 6:204. https://doi. org/10.3389/fpsyg.2015.00204

51. Šabanović S (2014) Inventing Japan's 'robotics culture': The repeated assembly of science, technology, and culture in social robotics. Soc Stud Sci 44:342-367. https://doi.org/10.1177/0306 312713509704

52. Kamide H, Arai T (2017) Perceived comfortableness of anthropomorphised robots in U.S. and Japan. Int J Soc Robot 9:537-543. https://doi.org/10.1007/s12369-017-0409-8

53. Bajones M, Weiss A, Vincze M (2017) Investigating the influence of culture on helping behavior towards service robots. In: HRI 17: proceedings of the companion of the 2017 ACM/IEEE international conference on human-robot interaction. ACM

54. Belpaeme T, Baxter P, de Greeff J, Kennedy J, Read R, Looije $R$ et al (2013) Child-robot interaction: perspectives and challenges. In: Herrmann G, Pearson M, Lenz A, Bremner P, Spiers A, Leonards U (eds) Social robotics, vol 8239. Springer, New York, pp 452-459

55. Ros R, Nalin M, Wood R, Baxter P, Looije R, Demiris $\mathrm{Y}$ et al (2011) Child-robot interaction in the wild: advice to the aspiring experimenter. In: ICMI'11: 13th international conference on multimodal interfaces. ACM

56. Shiomi M, Hagita N (2017) Social acceptance toward a childcare support robot system: web-based cultural differences investigation and a field study in Japan. Adv Robot 31:727-738. https:// doi.org/10.1080/01691864.2017.1345322

57. Onishi N (2006) In a wired South Korea, robots will feel right at home. The New York Times. https://www.nytimes.com/2006/ 04/02/world/asia/in-a-wired-south-korea-robots-will-feel-rightat-home.html. Accessed 20 Feb 2020

58. Li D, Rau PL, Li Y (2010) A cross-cultural study: effect of robot appearance and task. Int J Soc Robot 2:175-186. https://doi.org/ 10.1007/s12369-010-0056-9

59. Lee HR, Šabanović S (2014) Culturally variable preferences for robot design and use in South Korea, Turkey and the United States.
In: HRI' 14 Proceedings of the 2014 ACM/IEEE international conference on human-robot interaction. ACM

60. Rosenthal-von der Putten AM, Kramer NC (2015) Individuals' evaluations of and attitudes towards potentially uncanny robots. Int J Soc Robot 7:799-824

61. Takayama L, Pantofaru C (2009) Influences on proxemic behaviors in human-robot interaction. In: 2009 IEEE/RSJ international conference on intelligent robots and systems IROS 2009. IEEE, St. Louis, MO, USA

62. Joose M, Lohse M, Pérez JG, Evers V (2013) What you do is who you are: the role of task context in perceived social robot personality. In: 2013 IEEE international conference on robotics and automation. IEEE, Karlsruhe, Germany

63. Takayama L, Ju W, Nass C (2008) Beyond dirty, dangerous and dull: what everyday people think robots should do. In: HRI'08: Proceedings of the 3rd ACM/IEEE international conference on human robot interaction.

64. Hochschild AR (2003) The managed heart: commercialization of human feeling. University of California Press, California

65. Hudson J, Orviska M, Hunady J (2017) People's attitudes to robots in caring for the elderly. Int J Soc Robot 9:199-210. https://doi. org/10.1007/s12369-016-0384-5

66. Mussakhoyayeva S, Sandygulova A (2017) Cross-cultural differences for adaptive strategies of robots in public spaces. In: 2017 26th IEEE international symposium on robot and human interactive communication (RO-MAN). IEEE, Lisbon, Portugal

67. Sanders EB-N, Stappers PJ (2008) Co-creation and the new landscapes of design. Int J Co-Creation Des Arts 4:5-18. https://doi. org/10.1080/15710880701875068

68. Lee HR, Sung J, Šabanović S, Han J (2012) Cultural design of domestic robots: a study of user expectations in Korea and the United States. In: 2012 21st IEEE international symposium on robot and human interactive communication (RO-MAN). IEEE, Paris, France

69. Salem M, Ziadee M, Sakr M (2014) Marhaba, how may I help you? Effects of politeness and culture on robot acceptance and anthropomorphism. In: 2014 9th ACM/IEEE international conference on human-robot interaction. IEEE, Bielefeld, Germany

70. Brown P, Levinson SC (1987) Politeness: some universals in language usage. Cambridge University Press, Cambridge

71. Haring KS, Silvera-Tawil D, Matsumoto Y et al (2014) Perception of an android robot in Japan and Australia: a cross-cultural comparison. In: Beetz M, Johnston B, Williams MA (eds) Social robotics. ICSR 2014. Lecture notes in computer science, vol 8755. Springer, Cham

72. Shinozawa K, Reeves B, Wise Ket al (2003) Robots as new media: a cross-cultural examination of social and cognitive responses to robotic and on-screen agents. In: Proceedings of annual conference of international communication association

73. Cassell J (2000) Nudge nudge wink wink: elements of face-toface conversation for embodied conversational agents. In: Cassell J, Sullivan J, Prevost S, Churchill E (eds) embodied conversational agents. MIT Press, Cambridge

74. Evers V, Maldonado H, Brodecki T, Hinds P (2008) Relational vs. group self-construal: untangling the role of national culture in HRI. In: 2008 3rd ACM/IEEE international conference on humanrobot interaction (HRI). IEEE, Amsterdam, Netherlands

75. Riek LD, Mavridis N, Antali S et al (2010) Ibn sina steps out: exploring Arabic attitudes toward humanoid robots. In: Proceedings of the 2nd international symposium on new frontiers in human-robot interaction, (AISB). AISB, Leicester, UK

76. Mavridis N, Katsaiti MS, Naef S et al (2012) Opinions and attitudes toward humanoid robots in the Middle East. AI Soc 27:517-534. https://doi.org/10.1007/s00146-011-0370-2

77. Fraune MR, Kawakami S, Šabanović S et al (2015) Three's company, or a crowd? The effects of robot number and behavior on 
HRI in Japan and the USA. In: Robotics: science and systems. Rome, Italy

78. Haring KS, Silvera-Tawil D, Takahashi T et al (2015) Perception of a humanoid robot: a cross-cultural comparison. In: 2015 24th IEEE international symposium on robot and human interactive communication (RO-MAN). IEEE, Kobe, Japan

79. Haring KS, Silvera-Tawil D, Watanabe K et al (2016) The influence of robot appearance and interactive ability in HRI: a cross-cultural study. In: International conference on social robotics. Springer, Cham, pp 392-401

80. Joosse MP, Poppe RW, Lohse M et al (2014) Cultural differences in how an engagement-seeking robot should approach a group of people. In: Proceedings of the 5th ACM international conference on collaboration across boundaries: culture, distance \& technology. ACM

81. Rau PP, Li Y, Li D (2009) Effects of communication style and culture on ability to accept recommendations from robots. Comput Hum Behav 25:587-595. https://doi.org/10.1016/j.chb.2008.12.0 25

82. Matsumoto D (2006) Culture and nonverbal behavior. In: Manusov V, Patterson ML (eds) The Sage handbook of nonverbal communication. Sage Publications, Thousand Oaks, pp 219-235

83. Burgoon JK (1994) Nonverbal signals. In: Knapp ML, Miller GR (eds) Handbook of interpersonal communication, 2nd edn. Sage, Thousand Oaks, pp 229-285

84. Trovato G, Kishi T, Endo N et al (2013) Cross-cultural perspectives on emotion expressive humanoid robotic head: Recognition of facial expressions and symbols. Int J Soc Robot 5:515-527. https://doi.org/10.1007/s12369-013-0213-z

85. Suzuki S, Fujimoto Y, Yamaguchi T (2011) Can differences of nationalities be induced and measured by robot gesture communication? In: IEEE 2011 4th international conference on human system interactions, HSI 2011, pp 357-362

86. Eimler SC, Krämer NC, von der Pütten S (2011) Empirical results on determinants of acceptance and emotion attribution in confrontation with a robot rabbit. Appl Artif Intell 25(6):503-529

87. Shibata T, Wada K, Ikeda Y, Šabanović S (2009) Cross-cultural studies on subjective evaluation of a seal robot. Adv Robot 23(4):443-458

88. Rudovic O, Lee J, Mascarell-Maricic L, Schuller BW, Picard RW (2017) Measuring engagement in robot-assisted autism therapy: a cross-cultural study. Front Robot AI 4:36

89. Shahid S, Krahmer E, Swerts M (2014) Child-robot interaction across cultures: how does playing a game with a social robot compare to playing a game alone or with a friend? Comput Hum Behav 40:86-100

90. Neerincx A, Sacchitelli F, Kaptein R, Van Der Pal S, Oleari E, Neerincx MA (2016) Child's culture-related experiences with a social robot at diabetes camps. In: 11th ACM/IEEE international conference on human-robot interaction (HRI), pp 485-486

91. Torta E, Werner F, Johnson DO, Juola JF, Cuijpers RH, Bazzani M, Bregman J (2014) Evaluation of a small socially-assistive humanoid robot in intelligent homes for the care of the elderly. $\mathrm{J}$ Intell Rob Syst 76(1):57-71

92. Cortellessa G, Scopelliti M, Tiberio L, Svedberg GK, Loutfi, A, Pecora F (2008) A cross-cultural evaluation of domestic assistive robots. In: AAAI fall symposium: AI in eldercare: new solutions to old problems, pp 24-31

93. Lazarsfeld P, Merton R (1954) Friendship as a social process: a substantive and methodological analysis. In: Freedom and control in modern society. Van Nostrant, New York

94. McPherson M, Smith-Lovin L, Cook JM (2001) Birds of a feather: homophily in social networks. Ann Rev Sociol 27:415-444

95. Meltzoff AN (2007) 'Like me': a foundation for social cognition. Dev Sci 10(1):126-134
96. Wang L, Rau PP, Evers V, Robinson BK, Hinds P (2010) When in Rome: the role of culture \& context in adherence to robot recommendations. In: 5th ACM/IEEE international conference on human-robot interaction (HRI), Osaka, pp 359-366

97. Trovato G, Kishi T, Endo N, Zecca M, Hashimoto K, Takanishi A (2013) Cross-cultural perspectives on emotion expressive humanoid robotic head: recognition of facial expressions and symbols. Int J Soc Robot 5(4):515-527

98. Makatchev M, Simmons R, Sakr M, Ziadee M (2013) Expressing ethnicity through behaviors of a robot character. In: 8th ACM/IEEE international conference on human-robot interaction (HRI), Tokyo, pp 357-364

99. Eresha B, Häring M, Lugrin B, Andre E, Obaid M (2013) Investigating the influence of culture on proxemic behaviors for humanoid robots. Proc IEEE Int Workshop Robot Hum Interact Commun. https://doi.org/10.1109/ROMAN.2013.6628517

100. Trovato G, Ham JRC, Hashimoto K, Ishii H, Takanishi A (2015) Investigating the effect of relative cultural distance on the acceptance of robots. In: Tapus A, André E, Martin JC, Ferland F, Ammi M (eds) Social robotics. ICSR 2015. Lecture notes in computer science, vol 9388. Springer, New York

101. Spatola N, Anier N, Redersdorff S, Ferrand L, Belletier C, Normand A, Huguet P (2019) National stereotypes and robots' perception: the "made in" effect. Front Robot AI. https://doi.org/ 10.3389/frobt.2019.00021

102. Eyssel F, Kuchenbrandt D (2012) Social categorisation of social robots: anthropomorphism as a function of robot group membership. Br J Soc Psychol 51(4):724-731

103. Buolamwini J (2019) Artificial intelligence has a problem with gender and racial bias. Here's how to solve it. Time. https://time. com/5520558/artificial-intelligence-racial-gender-bias/

104. Wang Y, Kosinski M (2018) Deep neural networks are more accurate than humans at detecting sexual orientation from facial images. J Pers Soc Psychol 114(2):246-257. https://doi.org/10.1 037/pspa0000098

105. Hortensius R, Hekele F, Cross ES (2018) The perception of emotion in artificial agents. IEEE Trans Cognit Dev Syst 10(4):852-864

106. Klein A et al (2018) A practical guide for transparency in psychological science. Collabra Psychol 4(1):20. https://doi.org/10.152 5/collabra. 158

107. Lindsay DS (2015) Replication in psychological science. . Psychol Sci 26(12):1827-1832. https://doi.org/10.1177/0956797615 616374

108. Nosek A et al (2015) Estimating the reproducibility of psychological science. Science 349:943. https://doi.org/10.1126/science. aac4716

109. Cangelosi A, Schlesinger M (2015) Developmental robotics: from babies to robots. MIT Press, Boca Raton

110. Powell H, Michael J (2019) Feeling committed to a robot: why, what, when and how? Philos Trans R Soc B Biol Sci 374:20180039. https://doi.org/10.1098/rstb.2018.0039

111. Székely M, Powell H, Vannucci F, Rea F, Sciutti A, Michael J (2019) The perception of a robot partner's effort elicits a sense of commitment to human-robot interaction. Interact Stud. https:// doi.org/10.17605/OSF.IO/8W94H

112. Cross ES, Riddoch KA, Pratts J, Titone S, Chaudhury B, Hortensius R (2019) A neurocognitive investigation of the impact of socializing with a robot on empathy for pain. Philos Trans R Soc B 374:20180034. https://doi.org/10.1098/rstb.2018.0034

113. Giuliani M, Mirnig N, Stollnberger G, Stadler S, Buchner R, Tscheligi M (2015) Systematic analysis of video data from different human-robot interaction studies: a categorization of social signals during error situations. Front Psychol. https://doi.org/10. 3389/fpsyg.2015.00931 
114. Honig S, Oron-Gilad T (2018) Understanding and resolving failures in human-robot interaction: Literature review and model development. Front Psychol. https://doi.org/10.3389/fpsyg.2018. 00861

115. Cross ES, Liepelt R, Hamilton AFdC, Parkinson J, Ramsey R, Stadler W, Prinz W (2012) Robotic movement preferentially engages the action observation network. Hum Brain Mapp 33(9):2238-2254

116. Mori M (1970) The uncanny valley. Energy 7:33-35

117. Henschel A, Hortensius R, Cross ES (2020) Social cognition in the age of human-robot interaction. Trends Neurosci 43(6):373-384. https://doi.org/10.1016/j.tins.2020.03.013

118. Ng TK, Wang KWC, Chan W (2017) Acculturation and crosscultural adaptation: The moderating role of social support. Int $\mathbf{J}$ Intercult Relat 59:19-30. https://doi.org/10.1016/j.ijintrel.2017.0 4.012

119. Leite I, Castellano G, Pereira A, Martinho C, Paiva A (2012) Longterm interactions with empathic robots: evaluating perceived support in children. In: Ge S, Khatib O, Cabibihan J-J, Simmons R, Williams M-A (eds) Social robotics, vol 7621. Springer, Berlin, pp 298-307

120. Jones A, Castellano G (2018) Adaptive robotic tutors that support self-regulated learning: a longer-term investigation with primary school children. Int J Soc Robot 10:357-370. https://doi.org/10.1 007/s12369-017-0458-z

121. Ramge T (2019) Who's afraid of AI? Fear and promise in the age of thinking machines. Springer, South Melbourne

122. Phillips E, Zhao X, Ullman D, Malle BF (2018) What is humanlike? Decomposing robots' human-like appearance using the anthropomorphic roBOT (ABOT) database. In: Proceedings of the 2018 ACM/IEEE international conference on human-robot interaction, pp 105-113

Publisher's Note Springer Nature remains neutral with regard to jurisdictional claims in published maps and institutional affiliations.
Velvetina Lim is a PhD student at University College London's School of Management, within the Organisations and Innovation group. She holds an MRes in Management from the UCL School of Management. In 2019, she received a Gorilla grant to study the influence of creativity on ethical choices. Her research interests lie at the intersection of creativity, social perceptions, and the use of artificial intelligence at work.

Maki Rooksby is a postdoctoral researcher in the Social Brain in Action (SoBA) laboratory, affiliated with the Institute of Neuroscience and Psychology at the University of Glasgow. In the SoBA Lab, Maki is responsible for a UK-Japan collaboration project to investigate the role of culture for HRI, focusing on our sense of social and interpersonal space, also known as proxemics. Maki originally trained and worked as a developmental psychologist specialising in pre-school children's understanding of figurative language (such as sarcasm), and autobiographical memory in infants. As a post-doc, Maki has been developing a much wider range of research interests and expertise. These include mental health in children, family relationships including attachment, the phenomenon of hikikomori (severe social withdrawal), with the role of technology running as an overarching theme throughout these interests.

Emily S. Cross is the director of the Social Brain in Action Laboratory, and currently shares a dual appointment as a Professor of Human Neuroscience based at the Department of Cognitive Science at Macquarie University in Sydney, Australia, and a Professor of Social Robotics based at the University of Glasgow in Glasgow, Scotland. Through her research, she uses behavioural and brain imaging tools to explore how different kinds of experience (including ageing, culture, and laboratory-induced training) shape how we perceive other agents and actions we encounter in a social world. She completed a $\mathrm{PhD}$ in cognitive neuroscience at Dartmouth College in 2008, following earlier training in psychology and dance. Since 2015 she has served as the PI on the Mechanisms and Consequences of Attributing Socialness to Artificial Agents (SOCIAL ROBOTS) research project funded by the European Research Council. 